\title{
¿PROMESAS IDEALISTAS? AMÉRICA LATINA EN TIEMPOS DE LA RESPONSABILIDAD DE PROTEGER
}

Mónica Serrano

EN ESTE ARTículo ME PROPONGo analizar las causas que empujaron a los países latinoamericanos a apoyar o rechazar el principio de la responsabilidad de proteger (RdeP). Desde la última década del siglo xx, los líderes de América Latina han sopesado los méritos de este principio para prevenir o actuar ante crímenes atroces, frente al riesgo de intervención externa. Con ese propósito examino algunos de los factores que han contribuido a forjar las decisiones de los diplomáticos y actores latinoamericanos con respecto a la RdeP. Con base en el análisis de los argumentos que han definido las diversas posturas de los países latinoamericanos en los debates internacionales en torno a la RdeP, me ocupo también del papel que la región ha desempeñado en los esfuerzos internacionales para desarrollar y consolidar una norma internacional sobre RdeP. En la historia reciente de los países latinoamericanos se encuentra una de las claves para entender su apoyo o rechazo a la RdeP. Como este estudio intentará mostrar, en la evaluación que un país hace de los costos y beneficios potenciales de una respuesta multilateral al riesgo inminente de crímenes atroces, la historia pesa. ${ }^{1} \mathrm{Al}$ analizar y

${ }^{1}$ La definición de "crímenes atroces" empleada en este artículo alude a los delitos internacionales codificados en los párrafos 138 y 139 relativos a la Responsabilidad de Proteger del Documento Final de la Cumbre de la Organización de Naciones Unidas de 2005. Estos delitos son: genocidio, crímenes de guerra, crímenes de lesa humanidad y depuración étnica. Aunque este último no tiene aún un estatus de delito internacional, el acto de depuración étnica puede dar lugar a responsabilidad internacional al amparo de los otros tres delitos codificados en 
contrastar las diversas posturas encontramos que aquellos países que han sido sacudidos por episodios violentos de violaciones masivas de derechos humanos han mostrado una mayor apertura hacia la RdeP. En efecto, el legado de violaciones masivas de derechos humanos de gobiernos militares y autoritarios, así como los esfuerzos enfilados a saldar deudas de impunidad tras la democratización permiten explicar el interés de muchos países latinoamericanos en la lógica de prevención de la RdeP. La simpatía que este principio logró despertar en varios países no podría explicarse sin tomar en consideración la importancia de la evolución y práctica de las normas de derechos humanos en la región. Los principios normativos que están en la base de la RdeP se encontraban ya profundamente arraigados en las leyes de muchos Estados latinoamericanos. No obstante, en el entorno actual de regresión de la protección a los derechos humanos en el mundo y en la región es posible esperar que la participación de América Latina en el desarrollo normativo de la RdeP decline. Más aún, como se apunta en la conclusión, la rampante criminalidad y violencia homicida que hoy sacude a la región ha puesto en duda la capacidad de los gobiernos latinoamericanos de prevenir la perpetración de crímenes de guerra y de lesa humanidad y de proteger a su población de crímenes atroces.

\section{INTRODUCCIÓN}

A lo largo del siglo veinte, la recurrencia de crisis cívico-militares y la proclividad a la intervención militar en América Latina impidieron el desarrollo y consolidación de sistemas electorales, legislativos y judiciales fuertes e independientes en la región. ${ }^{2}$ Aunque

estos párrafos. A/RES/60/1. párrafo 138 y párrafo 139. Para una definición más amplia, véase Robert I. Rotberg, "Deterring Mass Atrocity Crimes: The Cause of our Era”, en Robert I. Rotberg (ed.), Mass Atrocity Crimes: Preventing Future Outrages, Washington, D. C., Brookings Institution Press, 2010, pp. 1-24.

${ }^{2}$ En América Latina, ha sido habitual la presencia de gobiernos y mandatarios militares desde inicios del siglo xIx. De hecho, en la región hubo golpes militares de manera relativamente constante antes de la Revolución cubana. Los estudios sobre los golpes militares ocurridos en el periodo que abarca de la déca- 
encontramos, sin duda, episodios importantes de gobiernos democráticos, no sólo llegaron por oleadas, sino que tendían a ser frágiles y crónicamente inestables. En países como Argentina, Bolivia, Perú, Ecuador, El Salvador, Honduras y Guatemala, las fuerzas armadas permanecieron como actores políticos clave, dominando la escena política y el gobierno durante buena parte del siglo pasado. En otros países, como Chile, Brasil y Uruguay, los militares intervinieron en momentos críticos, convencidos de la necesidad de someter a la sociedad, aunque ello supusiera el recurso a métodos brutales y a "reescribir la historia de sus naciones". ${ }^{3}$ Para la segunda mitad del siglo veinte, la Revolución cubana y la lucha contra el comunismo añadieron una nueva dimensión a la propensión de los actores e instituciones militares latinoamericanos a intervenir violentamente en la política. En efecto, tras el fracaso de los múltiples intentos de Estados Unidos por derrocar a Fidel Castro y la institucionalización de un régimen socialista revolucionario en Cuba, comenzaría un periodo sin precedentes de cooperación militar entre Estados Unidos y las corporaciones castrenses de la región.

Desde el fin de la Segunda Guerra Mundial, la presencia de una red de instituciones militares, consejos de defensa y programas de entrenamiento había permitido a Washington mantener y profundizar su influencia sobre los asuntos militares y de seguridad en la región. Pero, para principios de la década de 1960, la Revolución cubana sería el catalizador de una nueva etapa de intensa

da de 1820 hasta 1960 hallaron una correlación estadística positiva entre las fluctuaciones económicas internacionales y los ciclos de golpes, pero también en momentos en los que las elecciones amenazaban con imponer un presidente inaceptable, cuando los intereses de las fuerzas armadas se veían amenazados, cuando los conflictos no podían resolverse a través de los canales políticos civiles o cuando los dirigentes militares percibían que "la patria" estaba a merced de intereses extranjeros domésticos. Brian Loveman, For La Patria: Politics and the Armed Forces in Latin America, Wilmington, Scholarly Resources, 1999, p. 174.

${ }^{3}$ Loveman, op. cit., p. xvi. Para un análisis exhaustivo y detallado de la abundante bibliografía sobre el colapso democrático y una interpretación más reciente del apoyo ciudadano a la democracia, así como el comportamiento y elecciones de las élites en momentos de crisis, véase Nancy Bermeo, Ordinary People in Extraordinary Times: The Citizenry and the Breakdown of Democracy, Princeton, Princeton University Press, 2003. 
cooperación militar entre Estados Unidos y diversos gobiernos latinoamericanos orientada a combatir la subversión y la supuesta amenaza del comunismo internacional. ${ }^{4}$ De este modo, durante las décadas de 1960 y 1970, ante el temor de que la Revolución cubana pudiera extenderse a otras latitudes, las élites estadounidenses y latinoamericanas decidieron apuntalar la cooperación militar y profundizar las acciones conjuntas contra la amenaza comunista. El efecto inmediato de esta nueva etapa de cooperación militar fue la subordinación de la agenda de la democracia, las libertades civiles y los derechos humanos a los imperativos del anticomunismo y la estabilidad política. Aunque el modelo del "foco" y los movimientos insurgentes no consiguieron contagiar la revolución en otras latitudes del continente, la cooperación militar y los esfuerzos contrarrevolucionarios dejarían una huella indeleble en las instituciones militares de la región. Pero estos sucesos no sólo incidirían en el carácter de la institución armada, sino que influirían de manera decisiva en la interacción cotidiana entre las fuerzas armadas y sus sociedades. Estos cambios anunciaban algo grave que, antes de lo esperado, marcaría el rumbo de la historia de los derechos humanos en la región. Sin duda, entre las consecuencias más dramáticas de estos desarrollos podemos mencionar la cadena de golpes e intervenciones militares que tuvieron lugar entre 1963 y 1979, así como la consecuente institucionalización de regímenes militares decididos a embarcarse en profundas transformaciones políticas e institucionales de largo aliento. ${ }^{5}$ A lo largo

${ }^{4}$ Como lo apunta Brian Loveman, para finales de 1963 Washington consideraba prioritaria la contrainsurgencia militar y estaba dispuesto a entrar en alianza con los dictadores de la región que quisieran sumarse a la cruzada anticomunista. Loveman, op. cit., p. 176; Abraham F. Lowenthal, "Two Hundred Years of American Foreign Policy: The United States and Latin America: Ending the Hegemonic Presumption”, Foreign Affairs, octubre de 1976.

${ }^{5}$ La participación política de los militares y el ascenso e institucionalización de gobiernos militares en América Latina dio lugar a una copiosa bibliografía. Véanse, entre otros, Robert A. Potash, The Army and Politics in Argentina, 19451962: Perón to Frondizi, Londres, The Athione Press, 1980; David P. Rock, "Military Politics in Argentina 1966-1973”, en Brian Loveman y Thomas M. Davies (eds.), The Politics of Antipolitics: The Military in Latin America, Lincoln, University of Nebraska, 1978, pp. 236-241; Brian Loveman y Thomas M. Davis (eds.), The Politics of 
de estos años, los episodios de gobiernos dictatoriales y militares, haciéndose del poder con la intención declarada de doblegar a sus sociedades con métodos extremos y en algunos casos, como en Argentina, de someterlas a procesos de "reingeniería social", se repitieron a lo largo y ancho de la región. En efecto, buena parte de los regímenes militares que se propagaron e institucionalizaron en América Latina en estas décadas compartieron un mismo objetivo: impedir por todos los medios que "la patria" pudiera caer en una revolución. Más que temer las consecuencias del recurso a métodos extremos, quienes tuvieron a su mando el gobierno autoritario o militar buscaron, de manera deliberada, infundir temor en la población. No sólo no repararon en los costos que podía entrañar la percepción de un gobierno feroz y arbitrario, sino que vieron en ello una ventaja política. En consecuencia, una vez que los sucesivos gobiernos militares en Ecuador (1963), Brasil (1964) Argentina (1966), Perú (1968), Chile (1973) y Uruguay (1973), por mencionar algunos, pusieron en marcha los planes para extinguir la subversión interna y la amenaza de la influencia comunista cubana y soviética, las violaciones masivas a los derechos humanos se multiplicaron en forma exponencial. ${ }^{6}$

En diciembre de 1982, al recibir el Premio Nobel en Estocolmo, Gabriel García Márquez aludió en forma elocuente a una realidad de crímenes atroces que había ya cimbrado a la región. En el texto titulado "La soledad de América Latina", García Márquez se

\footnotetext{
Antipolitics: The Military in Latin America, $3^{\mathrm{a}}$ ed., rev. y amp., Oxford, Scholarly Resources, 1997; Alfred C. Stepan, The Military in Politics: Changing Patterns in Brazil, Princeton, Princeton University Press, 1971; y, del mismo autor, Rethinking Military Politics: Brazil and the Southern Cone, Princeton, Princeton University Press, 1988; Arturo Valenzuela, "Six Years of Military Rule in Chile: A Rapporteur's Report”, Woodrow Wilson Center, Latin American Program, Working Papers 109, 1982; Samuel J. Valenzuela y Arturo Valenzuela (eds.), Military Rule in Chile: Dictatorship and Oppositions, Baltimore, The Johns Hopkins University Press, 1986; Samuel J. Fitch, The Armed Forces and Democracy in Latin America, Baltimore, The Johns Hopkins University Press, 1998; David Pion-Berlin, The Ideology of State Terror: Economic Doctrine and Political Repression in Argentina and Peru, Boulder, Lynne Rienner, 1989; y del mismo autor, Civil-Military Relations in Latin America: New Analytical Perspectives, Chapel Hill, University of North Carolina Press, 2001.
}

${ }^{6}$ Loveman, op. cit., p. 168. 
refirió a los trágicos legados de aquellos años en que los golpes y gobiernos militares se sucedían unos a otros en América Latina:

Los desaparecidos por motivos de la represión son casi 120000, que es como si hoy no se supiera dónde están todos los habitantes de la cuidad de Upsala. Numerosas mujeres encintas que fueron arrestadas dieron a luz en cárceles argentinas, pero aún se ignora el paradero y la identidad de sus hijos, que fueron dados en adopción clandestina o internados en orfanatos por las autoridades militares. Por no querer que las cosas siguieran así han muerto cerca de 200000 mujeres y hombres en todo el continente, y más de 100000 perecieron en tres pequeños y voluntariosos países de la América Central, Nicaragua, El Salvador y Guatemala. Si esto fuera en los Estados Unidos, la cifra proporcional sería de un millón 600000 muertes violentas en cuatro años.

De Chile, país de tradiciones hospitalarias, ha huido un millón de personas: el 12\% de su población. El Uruguay, una nación minúscula de dos y medio millones de habitantes que se consideraba como el país más civilizado del continente, ha perdido en el destierro a uno de cada cinco ciudadanos. La guerra civil en El Salvador ha causado desde 1979 casi un refugiado cada 20 minutos. El país que se pudiera hacer con todos los exiliados y emigrados forzosos de América Latina, tendría una población más numerosa que Noruega. ${ }^{7}$

$\mathrm{Y}$, sin embargo, es justamente en estas experiencias aciagas que encontramos las raíces de un régimen regional de derechos humanos relativamente robusto en el que, tiempo después, las ambiciones normativas de la responsabilidad de proteger encontrarían resonancia. De ahí que en este artículo me proponga identificar y explicar la contribución de los países latinoamericanos al desarrollo y consolidación de las normas de derechos humanos que están en la base del principio de la RdeP. En la primera sección me ocupo del papel que las naciones latinoamericanas desempeñaron en

${ }^{7}$ Gabriel García Márquez, "La soledad de America Latina”, discurso para el Premio Nobel, 8 de diciembre de 1982, disponible en http://www.nobelprize. org/nobel_prizes/literature/laureates/1982/marquez-lecture-sp.html 
la revolución internacional de los derechos humanos de la segunda mitad del siglo veinte. El punto de partida es justamente la contribución de los países de América Latina en la etapa temprana de creación del régimen internacional de los derechos humanos. Analizo después la práctica de los derechos humanos, en especial los esfuerzos épicos de protección desplegados durante los años mismos de las dictaduras y gobiernos militares. No sólo los derechos humanos no sucumbieron ante el asedio de las dictaduras militares, sino que, empujados por diversos actores, dejaron ver su potencial de resistencia y de transformación del marco regional incipiente de derechos humanos en un sistema de protección de crímenes de lesa humanidad. En efecto, el estudio de la práctica de los estándares y normas de derechos humanos, ya sea en el contexto de gobiernos militares o de transición y consolidación democráticas, resulta útil para hacer inteligible el ejercicio de liderazgo de los países y sociedades latinoamericanas tanto en la política regional como internacional de los derechos humanos. Como sabemos, en su tránsito del autoritarismo y la dictadura militar al gobierno democrático, los países latinoamericanos se embarcaron por diversos caminos políticos y distintas rutas de derechos humanos. Algunos optaron por la consolidación, otros emprendieron el camino de la democracia popular y otros más parecieron retroceder a prácticas autoritarias. Al seguir el trazo de estas distintas rutas podemos descifrar el papel que los países latinoamericanos desempeñarían en los esfuerzos nacionales e internacionales para atajar la impunidad por crímenes atroces y anticipar también su posición en el desarrollo del principio de la RdeP. La participación activa de Argentina en la creación de la Corte Penal Internacional, el respaldo otorgado por buena parte de los países latinoamericanos a dicha institución o la actitud favorable de algunos países de la región al proyecto de la RdeP no podrían explicarse sin volver la mirada hacia el pasado, a los escombros de la represión. Si, en términos generales, la transición a la democracia abrió nuevos horizontes, normativos y prácticos, a los derechos humanos, y en algunos países ofreció también un contexto propicio para la valoración de la RdeP, las condiciones de inseguridad y de violencia criminal, que en tiempos más recientes han arraigado en América Latina, han 
reavivado las dudas sobre la vigencia de los derechos humanos en la región. Con 36\% del total de las 437000 muertes provocadas por homicidio intencional o doloso registradas a nivel mundial y $25 \%$ de los homicidios intencionales mundiales concentrados en cuatro países -Brasil, Colombia, México y Venezuela-, la capacidad de los países latinoamericanos de respetar y mantener su apoyo a las normas de derechos humanos, incluida la RdeP, parece estar en duda. ${ }^{8}$ Las consecuencias de estas tendencias sobre el comportamiento normativo de los países latinoamericanos en torno a los derechos humanos, la justicia de transición y la RdeP son, pues, objeto de una breve reflexión en la conclusión.

AmÉRICA Latina y La POLÍtica INTERNACIONAL

DE LOS DERECHOS HUMANOS

En el estudio de la contribución de los países latinoamericanos al desarrollo y consolidación de las normas e instituciones internacionales de derechos humanos, incluida la responsabilidad de proteger, sobresalen dos grandes vertientes. La primera alude al papel que diplomáticos y estadistas latinoamericanos desempeñaron en la construcción del régimen internacional de derechos humanos en los albores de la segunda posguerra. Conviene subrayar que la participación activa de diplomáticos latinoamericanos en este proceso no podría explicarse sin tomar en cuenta el arraigo de tradiciones constitucionales liberales en la región. No sólo encontramos codificados en estas tradiciones buena parte de los principios que hoy asociamos a la cultura y práctica de los derechos humanos, sino que desde principios del siglo veinte los derechos humanos ocuparon un lugar destacado en las conferencias regionales. ${ }^{9}$ Pero al historial

${ }^{8}$ UNODC, "Global Study on Homicide 2013. Trends, Contexts, Data", disponible en: https://www.unodc.org/documents/gsh/pdfs/2014_GLOBAL_HOMICIDE_BOOK_web.pdf; Robert Muggah y Nathalie Alvarado, "Latin America Could Cut Its Murder Rate by 50 Percent. Here's How", Americas Quarterly, 4 de octubre de 2016, disponible en https://igarape.org.br/en/latin-america-could-cut-its-murder -rate-by-50-percent-heres-how/

${ }^{9}$ El concepto de América Latina como región suele derivarse de las experien- 
de los Estados latinoamericanos en tanto empresarios de normas internacionales de derechos humanos e "innovadores del orden internacional" se añade el impacto de la experiencia misma de violaciones graves y masivas de los derechos humanos en la región. Ambos hechos deben ser considerados como cimientos imprescindibles de la arquitectura legal regional para la protección de dichas garantías y como factores explicativos de la presencia latinoamericana en la política internacional de los derechos humanos. ${ }^{10}$ No faltan ejemplos en la historia regional de los derechos humanos que permitan ilustrar la forma en que esas experiencias dolorosas de violaciones graves y, en ocasiones, masivas de los derechos humanos se convirtieron en el motor, si no la causa, para la activación de la maquinaría de derechos humanos en la región. ${ }^{11}$

cias coloniales comunes, las influencias encontradas de la Iglesia católica y las tradiciones constitucionales liberales, y una búsqueda tenaz (aunque claramente inconsistente) de una modernidad de corte occidental. Sin embargo, estas experiencias comunes no hicieron de América Latina una entidad homogénea, pues no sólo las diferencias internas siguen siendo importantes y se resisten a las categorizaciones fáciles, sino que la pertenencia regional de cada país también está determinada por los cambios y dinámicas más generales, que los historiadores y los especialistas han relacionado con los diversos contextos y configuraciones. L. Whitehead, Latin America: A New Interpretation, Basingstoke, Palgrave MacMillan, 2006, pp. 222-223; Georges Couffignal, La nouvelle Amérique Latine. Laboratoire politique de l'Occident, París, Presses de Science Po, 2013; Andrew Hurrell, "Regional Powers and the Global System from a Historical Perspective", en Daniel Flemes (ed.), Regional Leadership in the Global System: Ideas, Interests and Strategies of Regional Powers, Farnham, Ashgate, 2010, pp. 15-17.

10 Jorge I. Domínguez, "International Cooperation in Latin America: The Design of Regional Institutions by Slow Accretion", en Amitav Acharya y Alastair I. Johnston (eds.), Crafting Cooperation: Regional International Institutions in Comparative Perspective, Cambridge, Cambridge University Press, 2008.

11 Véase, entre otros, Lawrence Weschler, A Miracle, a Universe: Settling Accounts with Torturers, Chicago, The University of Chicago Press, 1990 (reimpresión de 1998); Catalina Smulovitz, "The Past Is Never Past: Accountability and Justice for Past Human Rights Violations in Argentina”, en Popovski Vesselin y Mónica Serrano (eds.), After Oppression Transitional Justice in Latin America and Eastern Europe, Tokio, United Nations University Press, 2012; y "Commissions of Truth and Reconciliation: Argentina”, en Alex Boraine y Janet Levy (eds.), The Healing of a Nation? Justice in Transition, Ciudad del Cabo, 1995; Ezequiel González Ocantos, "Unsettling Accounts: Neither Truth Nor Reconciliation in Confessions of State 
a) La arquitectura regional de derechos humanos: el papel de los diplomáticos

La protección de los derechos humanos ya era un tema importante en la región desde tiempo atrás y desde por lo menos la década de 1920 había sido abordada en las sucesivas conferencias interamericanas. Pero no fue sino hasta los primeros años de la segunda posguerra cuando varias repúblicas latinoamericanas asumirían un papel central en el movimiento que llevaría los derechos humanos a la palestra internacional. La celebración de la Conferencia de Chapultepec sobre los "Problemas de la Guerra y de la Paz" de 1945 dejó ver la relevancia de los derechos humanos en la región. Las repúblicas americanas adoptaron entonces una resolución sobre la "Protección Internacional de los Derechos Fundamentales del Hombre", que sentaría, a su vez, las bases de un incipiente sistema regional para la protección de los derechos humanos. Poco después, en 1948, al suscribir la "Declaración Americana de los Derechos y Deberes del Hombre", los Estados americanos promulgaron el primer documento internacional de importancia referente a los derechos humanos. ${ }^{12}$ Como ocurrió con la Declaración

Violence", tesis de Doctorado en Ciencia Política, Universidad de Notre Dame, 2012; Leigh Payne, Unsettling Accounts: Neither Truth Nor Reconciliation in Confessions of State Violence, Durham, Duke University Press, 2008.

12 Basada en la teoría de los derechos naturales, esta declaración afirma que los derechos fundamentales del hombre "no nacen del hecho de ser nacional de determinado Estado, sino que tienen como fundamento los atributos de la persona humana”. La Declaración comprendía tanto derechos civiles y políticos, como económicos y sociales. Los derechos civiles y políticos ya estaban contenidos en las constituciones de la mayoría de las repúblicas de América Latina: igualdad ante la ley, derecho al debido proceso, derecho de petición y de reunión, libertad religiosa, protección contra arrestos arbitrarios, etc. Entre los derechos económicos y sociales se encuentran el de preservación de la salud y el bienestar, el de los beneficios de la cultura, el de tener un trabajo y una justa remuneración por el mismo. Los primeros compromisos adoptados por los Estados regionales relativos a los "ciudadanos naturalizados", los "extranjeros" y el asilo al parecer estaban destinados a fomentar un orden regional sustentando en los principios de no intervención. Robert K. Goldman, "History and Action: The Inter-American Human Rights System and the Role of the Inter-American Commission on Human Rights", $\mathrm{Hu}$ man Rights Quarterly, vol. 31, 2009, pp. 859-860. 
Universal de Derechos Humanos, la "Declaración Americana de los Derechos y Deberes del Hombre" no alcanzó el estatus de un instrumento legalmente vinculatorio. Sin embargo, lo que se debe destacar es que motivó a los Estados regionales a contemplar la construcción de un sistema regional de derechos humanos sobre los firmes cimientos del derecho de petición. Si bien la creación de una maquinaria con capacidad real para proteger los derechos humanos habría de tomar más de una década, ya desde 1948 los Estados regionales encomendaron al Comité Jurídico Interamericano la tarea de elaborar una convención y estatuto para la creación de una Corte Interamericana. En su momento, dicho tribunal asumió la responsabilidad de proteger los derechos que habían sido ya consagrados regionalmente.

De este modo, el compromiso que países como Brasil, Colombia, Cuba, República Dominicana, México y Panamá habían contraído con la causa de los derechos humanos contribuyó de manera importante a montar el andamio de un régimen regional. Es importante anotar que los intereses de los países de América Latina con respecto a los derechos humanos no estaban en modo alguno limitados a la región. En efecto, durante las negociaciones para la creación de la nueva organización mundial los diplomáticos latinoamericanos se sumaron al movimiento a favor de incluir referencias fundamentales a los derechos humanos en la Carta de las Naciones Unidas. ${ }^{13}$ En San Francisco, las repúblicas latinoamericanas, como región, apoyaron la idea de que la Carta debía contener una declaración de derechos humanos. Y, mientras que por su parte Colombia presentaba un borrador de preámbulo en el que se declaraba que la promoción de los derechos humanos constituía un catalizador fundamental para la creación de una organización internacional, en una propuesta conjunta, México, Brasil y República Dominicana calificaron la protección -no sólo promociónde los derechos humanos como una misión primordial de la nueva

${ }^{13}$ Kathryn Sikkink, "Latin American Countries as Norm Protagonists of the Idea of International Human Rights", sección especial de "Principles from the periphery: The Neglected Southern Sources of Global Norms", Global Governance, vol. 20, núm. 3, julio-septiembre de 2014. 
organización. De igual forma, Cuba, Chile y Panamá presentaron listas específicas y borradores de declaraciones relativas a esos derechos. No debe pues extrañar que analistas, como Morsink en su examen sobre la Declaración Universal de los Derechos Humanos, hayan reconocido el peso que tuvieron las ideas y actores latinoamericanos en el proceso de redacción de este texto universal. ${ }^{14} \mathrm{Ya}$ sea de manera individual o colectiva, las repúblicas latinoamericanas influyeron de manera significativa en el proceso que llevó a encomendar a la ONU tres tareas primordiales: codificar las normas internacionales sobre derechos humanos, fomentar una cultura global de derechos humanos e, igualmente importante, consolidar los derechos humanos como un tema estándar de las relaciones internacionales. ${ }^{15}$ De hecho, tras la participación activa de diplomáticos latinoamericanos y de otras latitudes en estos procesos, cobró fuerza la idea de los derechos humanos como un rasgo fundamental y constitutivo del orden internacional. Desde una perspectiva más pragmática, es claro que los Estados latinoamericanos vieron en el desarrollo de estos derechos y, en particular, de los sociales y económicos, una plataforma particularmente útil para atajar las desigualdades del orden internacional y demandar mayor equidad. ${ }^{16}$

${ }^{14}$ Johannes Morsink, The Universal Declaration of Human Rights: Origins, Drafting, and Intent, Filadelfia, University of Pennsylvania Press, 1999; Samuel Moyne, "The Universal Declaration of Human Rights of 1948 in the History of Cosmopolitanism”, Critical Inquiry, vol. 40, núm. 4, 2014, pp. 365-384. Si bien Moyne reconoce la pluralidad de visiones y posibilidades en relación con los derechos humanos, su análisis de la Declaración Universal de los Derechos Humanos omite por completo la contribución de América Latina.

${ }^{15}$ Ken Booth y Tim Dunne, "Learning beyond Frontiers", en Tim Dunne y Nicholas Wheeler (eds.), Human Rights in Global Politics, Cambridge, Cambridge University Press, 1999, p. 304; Andrew Hurrell, "International Society and the Study of Regimes: A Reflective Approach”, en Wolker Rittberg (con Peter Mayer) (ed.), Regime Theory and International Relations, Oxford, Clarendon Press, 1993, p. 54; Kathryn Sikkink, "Human Rights, Principled Issue-Networks, and Sovereignty in Latin America”, International Organization, vol. 47, núm. 3, verano de 1993; Sikkink, op. cit., 2014.

${ }^{16}$ Anthony Padgen, "Human Rights, Natural Rights and European Imperial Legacy", Political Theory, vol. 31, núm. 2, abril de 2003; Sikkink, op. cit., 1993; Kathryn Sikkink, Mixed Signals: US Human Rights Policy towards Latin America, Ithaca, 
No cabe duda de que estas primeras iniciativas a favor de los derechos humanos se dieron en un contexto regional firmemente anclado en los principios de la no intervención y la soberanía nacional. Aun así, no es descabellado suponer que en América Latina la tensión entre la decisión de respetar el principio de no intervención y los compromisos internacionales de derechos humanos pudo haber sido atemperada gracias a la presencia de la doctrina de la soberanía popular, piedra angular de las tradiciones jurídicas de la región. ${ }^{17}$ Además sería difícil negar que la postura inicial de los países latinoamericanos -que reconocía la necesidad de elevar el estatus de los derechos humanos al ámbito internacional al tiempo que se oponía a cualquier tipo de monitoreo o injerencia multilateral- era perfectamente congruente con las tendencias internacionales que imperaron en el mundo en esos años. ${ }^{18}$ Pero, para finales de la década de 1950, algunas señales parecían anunciar una posible reconciliación entre las lógicas de la no intervención y los derechos humanos en la región. Poco a poco, los Estados latinoamericanos fueron abandonando la postura rígida sobre la supremacía de la soberanía y -en parte inspirados por el ejemplo europeo- fueron aceptando, de manera progresiva, la idea de un sistema de normas de derechos humanos que pudiera ser regionalmente instrumentado. De este modo, al concluir la década, gracias a una serie de decisiones pudieron establecerse las bases para el

Cornell University Press, 2004, pp. 24-33; Sikkink, op. cit., 2014; Paulina Ochoa, "Paradoxes of Popular Sovereignty: A View from Spanish America", The Journal of Politics, vol. 74, núm. 4, octubre de 2012; Jack Donnelly, "Universal Human Rights: A Critique", en Tim Dunne y Nicholas Wheeler (eds.), Human Rights in Global Politics, Cambridge, Cambridge University Press, 1999, p. 73.

17 Ochoa, op. cit.

18 Durante su primera sesión, realizada en 1947, la Comisión de Naciones Unidas sobre Derechos Humanos concluyó que no tenía "facultades para tomar acción alguna con respecto a quejas sobre violaciones de derechos humanos" (citado en Donnelly, op. cit., p. 73). Asimismo, la precedencia del principio de no intervención se hizo evidente en los reiterados debates que se suscitaron en las conferencias interamericanas. En efecto, al abordar las tensiones y contradicciones entre la protección internacional o regional de los derechos humanos y la soberanía regional, los Estados latinoamericanos dejaron ver su inclinación en favor de la no intervención. 
surgimiento eventual de un sistema regional efectivo de protección de los derechos humanos. Así, durante la Quinta Reunión de Consulta de Ministros de Relaciones Exteriores, celebrada en Chile en 1959, los Estados de la región abordaron el tema de la posible relación entre regímenes antidemocráticos y una deficiente protección de los derechos humanos. La resolución emanada de esta conferencia no sólo llevó a la adopción de una convención, sino que ratificó la decisión de confiar la protección regional de los derechos humanos a dos instancias: una Comisión y un Tribunal regional.

Poco después, en el verano de 1960, el Consejo de la Organización de Estados Americanos (oEA) aprobó el estatuto de la Comisión Interamericana de Derechos Humanos como una "entidad autónoma”, responsable de elevar la conciencia sobre derechos humanos entre los pueblos del continente, de hacer recomendaciones a los gobiernos regionales y de preparar estudios de caso e informes. Aunque la redacción de la Convención resultó más compleja y prolongada de lo pensado -debido entre otras cosas al impacto que tuvo la Revolución cubana en las dinámicas regionales y a la presencia de desacuerdos en torno a los términos del contenido del documento-, el texto final fue finalmente aprobado durante una Conferencia Interamericana Especial que tuvo lugar en San José, Costa Rica, en noviembre de 1969. ${ }^{19}$

$\mathrm{Al}$ igual que en Europa, el sistema interamericano de derechos humanos fue diseñado para que descansara sobre dos pilares: la Comisión y un tribunal regional de derechos humanos con autoridad para resolver casos específicos de violaciones de derechos humanos. Sería un error desestimar las disparidades que marcaron el surgimiento y desarrollo de los sistemas de derechos humanos en

${ }^{19}$ La entrada en vigor de la Convención, en 1978, estableció de hecho un sistema regional dual sobre derechos humanos. Aunque la Convención constituyó el principal referente sobre derechos humanos para los Estados miembros, la Declaración y la Carta de la oEA siguieron siendo los principales puntos de referencia para los Estados regionales que no formaban parte de la Convención. La Comisión puede resolver sobre casos que se sometan contra los dos grupos de Estados, pero sólo puede remitir casos a la Corte Interamericana contra Estados que hayan ratificado la Convención y aceptado la jurisdicción de dicha Corte. Goldman, op. cit., pp. 862-866. 
Europa y en América Latina. Sin embargo, en ambos continentes, la creación de procedimientos internacionales de aplicación de la ley, generados a partir de demandas individuales y de una jurisdicción obligatoria, inclinaría la balanza normativa en contra de la no intervención y sentaría las bases para la activación futura de sistemas regionales efectivos de protección de derechos humanos.

Ya en 1965, una resolución de la oeA había ampliado las funciones y facultades de la Comisión Interamericana de Derechos Humanos y había también demandado que este órgano prestara especial atención a los derechos encarnados en la Declaración Americana de 1948: derecho a la vida, a la libertad y a la seguridad personal; derecho a la igualdad ante la ley, al debido proceso y a un juicio justo; derecho a la libertad religiosa, a la libertad de investigación, opinión, expresión, y protección de detenciones arbitrarias. Para la segunda mitad de la década de 1960, el impacto de esos avances cobró fuerza, empoderando a la Comisión para actuar de manera importante en dos crisis regionales: en República Dominicana, en 1965, y en el contexto de las hostilidades entre Honduras y El Salvador, en 1969.

A lo largo de los años de 1960, el sistema regional de derechos humanos fue evolucionando subrepticiamente, a veces estimulado por las decisiones de los gobiernos regionales, pero más a menudo por la divulgación de las investigaciones e informes sobre situaciones y países específicos de la Comisión. Los primeros informes de la Comisión relativos a los presos políticos en Cuba (1962, 1963 y 1967), junto con los documentos internos sobre la situación de los derechos humanos en Guatemala, República Dominicana, Paraguay y Nicaragua, posicionaron a la organización como "guardián y censor" de las tendencias presentes en el hemisferio en materia de derechos humanos.

Es cierto que, en sus primeras deliberaciones, la Comisión había declarado que carecía de facultades para pronunciarse y resolver sobre demandas presentadas por individuos o grupos contra Estados miembros. Sin embargo, ya desde 1960 los miembros del organismo llegaron a una conclusión fundamental: la Comisión podría "tomar conocimiento" de dichas demandas a título informativo. Y poco después de 1965, cuando la Comisión participó en 
varios asuntos relacionados con derechos humanos, algunos observadores concluyeron que con sus acciones y conclusiones éste órgano había de hecho ya dado cauce a una "reinterpretación sustancial de la doctrina de la no intervención tan celosamente guardada" en América Latina. ${ }^{20}$ En efecto, durante sus primeros cinco años, la Comisión no sólo reafirmó su autoridad para investigar las demandas de individuos y para hacer recomendaciones a los Estados regionales, sino que elaboró informes sin precedentes que contribuyeron a documentar y denunciar violaciones graves y en algunos casos masivas de derechos humanos.

\section{b) La Guerra Fría, el Estado de terror y la política regional sobre derechos humanos}

El inicio de la Guerra Fría estuvo acompañado por la propagación del autoritarismo y la sucesión de gobiernos y dictaduras militares en la región. En esas circunstancias no era difícil imaginar que vendrían tiempos azarosos para el desarrollo y consolidación de un régimen regional de derechos humanos. Como ocurrió a nivel mundial, en América Latina el avance en materia de derechos humanos fue más bien lento y errático. Por un lado, tanto el impacto de la Guerra Fría como la presencia de un entorno hostil y tortuoso, dominado por numerosos regímenes autoritarios y militares que se extendieron por la región, frenó cualquier otra iniciativa de derechos humanos. Por otro lado, en aquellos países en los que las normas de derechos humanos habían sido legalmente aceptadas y codificadas, su justa aplicación terminó en manos de gobiernos nacionales adversos a los derechos humanos y a menudo, también, proclives a la represión. De esta forma, durante los años de la Guerra Fría, en América Latina como en el resto del mundo la protección de los derechos humanos terminó subordinada a los intereses estratégicos y de seguridad de los gobiernos en turno. De ahí que el poder de los conceptos y normas relativos a los derechos

${ }^{20}$ Esto fue lo que opinó el profesor Durward V. Sandifer, quien fuera miembro de la Comisión. Citado en Goldman, op. cit., p. 867. 
humanos permaneciera temporalmente eclipsado. En efecto, las secuelas de la Guerra Fría, aunadas al impacto de la Revolución cubana, sumieron a varios países en una crisis que no sólo puso en duda su compromiso con los derechos humanos, sino que en muchos casos desembocó en situaciones de terror y represión masiva a manos de las agencias de seguridad del Estado. Y algo más, desde el Cono Sur hasta Centroamérica, la doctrina de seguridad nacional que en esos años amparó la cooperación militar entre Estados Unidos y las fuerzas latinoamericanas proveyó los argumentos necesarios para justificar la ola de políticas represivas que abatiría a la región en las décadas subsecuentes.

Así, en el periodo de las décadas de 1970 y 1980, las iniciativas interamericanas a favor de los derechos humanos fueron frenadas o quedaron simplemente atrapadas en la turbulencia de las corrientes desatadas por la Guerra Fría. Debe ser claro, sin embargo, que la realidad violenta que descendía sobre América Latina no condujo a una parálisis total. De manera inesperada, en los circuitos regionales e internacionales de derechos humanos comenzó a forjarse una voluntad férrea que opondría resistencia y que apertrechada con argumentos de derechos humanos buscaría desafiar a las fuerzas represivas. Justo cuando las naciones de América Central y del Cono Sur se hallaban en la cúspide del terror autoritario, activistas y organizaciones incipientes de derechos humanos se aferraron a los cimientos normativos que habían sido sentados durante interludios democráticos desde la década de 1960. Convencidos de que los compromisos regionales e internacionales de derechos humanos que los gobiernos habían contraído apenas unos años atrás debían significar algo, la movilización de estos actores buscó llamar a cuenta a estas autoridades. ${ }^{21}$ Por supuesto la realidad que envolvía a estos esfuerzos era estremecedora, pero juntos lograrían abrir paso a una etapa crucial para el futuro de los derechos humanos en la región.

${ }^{21}$ Svenja Blanke, “Civic Foreign Policy: Human Rights, Faith-Based Groups and US-Salvadorean Relations in the 1970s", The Americas, vol. 61, núm. 2, octubre de 2004, pp. 217-244. 
El ímpetu con que estos actores emprendieron la movilización regional se vio a su vez fortalecido por una serie de desarrollos que dominaron las dinámicas internacionales de derechos humanos en esos años. En efecto, algunos acontecimientos que tuvieron lugar en la escena internacional en la década de 1970 no sólo contribuirían a renovar la relevancia normativa de los derechos humanos, sino que impulsarían también la progresiva institucionalización del régimen internacional de derechos humanos. ${ }^{22}$ En 1973, justo cuando la dictadura de Pinochet avanzaba en Chile y la perspectiva de un colapso inmediato de los estándares y compromisos de derechos humanos se perfilaba como una posibilidad real, los cambios en los equilibrios políticos internos en Estados Unidos anunciaban el resurgimiento de la agenda de derechos humanos en la región y en el ámbito internacional. Es cierto que el golpe de Estado en Chile, como ocurriría en Argentina tres años después, hundiría a estos países en años de terror y represión. Pero también lo es que a partir de 1973, cuando el Congreso de Estados Unidos vinculó de manera explícita la ayuda exterior al desempeño en materia de derechos humanos por parte de los países receptores, los derechos humanos fueron elevados a la categoría de prioridad de política exterior. A medida que el autoritarismo y los gobiernos militares se extendieron en la región, la preocupación con respecto a los derechos humanos fue cobrando fuerza en Washington, Nueva York, así como en algunas capitales europeas. La inclusión de consideraciones de derechos humanos en la política exterior estadounidense y el creciente protagonismo de las organizaciones incipientes de

${ }^{22}$ Entre esos hechos estaban la primera Conferencia Mundial sobre Derechos Humanos, organizada en Teherán en 1968; la negociación del Acta Final de Helsinki, en 1975, que llevó al primer plano los derechos humanos en las relaciones y la relajación de las tensiones entre Oriente-Occidente; la entrada en vigor, en 1976, de las Convenciones Internacionales de Derechos Humanos -sobre derechos civiles y políticos y sobre derechos económicos, sociales y culturales-; la llegada del presidente Carter a la Casa Blanca y el surgimiento de los derechos humanos como una prioridad de la política exterior de Estados Unidos y desde luego la preeminencia que ganaron los organismos no gubernamentales de derechos humanos, simbolizada por el otorgamiento del Premio Nobel de la Paz a Amnistía Internacional en 1977. Sikkink, op. cit., 2004. 
derechos humanos, en particular la Oficina en Washington para Asuntos Latinoamericanos (woLA, por su nombre en inglés) y Amnistía Internacional, modificarían de tajo el entorno en el que operarían los regímenes represores. ${ }^{23}$ De este modo, frente a los acontecimientos trágicos en Chile y Argentina, por mencionar sólo dos casos, se fueron abriendo paso actores decididos a reavivar la lucha por la protección de los derechos humanos en la región y en el mundo.

En un periodo relativamente corto, que va de 1970 a 1978, los informes de casos específicos y de país permitieron a la Comisión Interamericana evaluar y exhibir la situación preocupante de los derechos humanos de muchos regímenes autoritarios y militares. Este fue particularmente el caso de los informes "país" que elaboró la Comisión sobre Chile (1974, 1976 y 1977), Paraguay y Uruguay (1978) y el informe pionero de 1980 sobre Argentina, tras la visita extraordinaria de la Comisión a ese país. La nota característica de estos informes fue la denuncia de la tendencia de las instituciones militares y de las estructuras de seguridad a recurrir de manera sistemática a tácticas brutales de represión.

La descripción elocuente de Tom Farer sobre la labor de la Comisión en Argentina ilustra con toda claridad la contribución crucial de este organismo al desarrollo y subsecuente institucionalización del régimen regional de derechos humanos. En su opinión, para 1978, la entrada en vigor de la Convención Americana sobre Derechos Humanos había empoderado a la Comisión, convirtiéndola "en un órgano acusatorio, una especie de "Gran Jurado Hemisférico" que de manera sorpresiva apareció en los rincones más problemáticos de América Latina con el afán declarado de

${ }^{23}$ Poco después del golpe de Estado en Chile, el wola fue creado por un grupo de individuos que, habiendo vivido y trabajado en América Latina, se propusieron sacar a la luz la verdad sobre lo que estaba ocurriendo. Wola puso en contacto a los legisladores y responsables de las políticas de Washington con testigos latinoamericanos que tenían información de primera mano sobre la naturaleza y magnitud de la represión que estaba ocurriendo en la región. No es difícil imaginar, pues, que gracias a estos esfuerzos Wola emergiera como un actor fundamental en el proceso que hizo del tema de los derechos humanos un asunto prioritario de la política exterior de Estados Unidos. 
"acumular todas las evidencias de crímenes graves y fechorías". Si bien en ese momento la Comisión aún se auto-limitaba y se abstenía de usar sus facultades para remitir casos a la Corte Interamericana, recurrió de manera incesante a los informes "país" para recabar evidencias y presentarlas a los "órganos políticos de la oEA y al tribunal de la opinión pública”. ${ }^{24}$

Es importante reconocer que esos informes, al igual que los de la Comisión Nacional sobre la Desaparición de Personas (Conadep) en Argentina o el informe posterior de la Comisión Nacional de Verdad y Reconciliación en Chile, se limitaban a describir y dar a conocer las violaciones a derechos humanos que habían ocurrido o continuaban ocurriendo en el presente. Pero también es importante llamar la atención al impacto ocasionado por estos informes en la activación del movimiento de derechos humanos. En efecto, por más terribles que fuesen, las revelaciones de estos estudios e investigaciones convencieron a víctimas y activistas de la necesidad imperiosa de actuar, contribuyendo a su paso a dar vida a movimientos locales de protección de los derechos humanos. En efecto, las evidencias de las violaciones graves y masivas a los derechos humanos que estos informes sacaron a la luz, pusieron al descubierto la distancia insondable entre los compromisos contraídos por los gobiernos latinoamericanos y la realidad aciaga de los derechos humanos. La influencia de estos informes fue palpable al

${ }^{24}$ Estas palabras fueron, de nuevo, expresadas por Tom Farer en la primera reunión de National R2P Focal Points (Puntos Focales Nacionales de RdeP) celebrada en Nueva York en 2010. En esa reunión, Farer resaltó la utilidad del modelo de la Comisión para abordar situaciones de crímenes atroces bajo el mandato de la Responsabilidad de Proteger. En su opinión, la experiencia de la Comisión, apoyada en un grupo pequeño, pero cohesionado de individuos empoderados con independencia y una autoridad moral impecable, mostró una notable capacidad para vigilar e investigar violaciones graves y masivas a los derechos humanos. La visita e informe subsecuente de la Comisión han sido ampliamente reconocidos como factores que contribuyeron a reducir y, posiblemente, detener la ola de desapariciones forzadas en Argentina. Véase Tom Farer, "The Rise of the Inter-American Human Rights Regime: No Longer a Unicorn, not yet an Ox”, Human Rights Quarterly, vol. 17, 1997; y "Report on the Situation of Human Rights in Argentina, Inter-American Commission on Human Rights, Organization of American States", Doc. OEA. Ser.L/V/II.49, doc.19, 1980. 
poner en manos de activistas, víctimas y familiares información y argumentos contundentes para exhibir y presionar a sus gobiernos. Sin duda, una consecuencia inevitable de estas primeras olas de activismo fue el impulso a nuevas y subsecuentes investigaciones, lo que a su vez contribuyó a gestar una nueva generación de demandas y compromisos sobre derechos humanos.

Motivados e impulsados por las estremecedoras revelaciones de la Comisión Interamericana y de las posteriores comisiones nacionales para la verdad, las víctimas y los actores involucrados en estos sucesos trágicos abrirían un nuevo capítulo en la historia de los derechos humanos de la región. En efecto, el contenido de estos informes contribuyó a develar el carácter sistemático de las violaciones a los derechos humanos y a identificar a las agencias de seguridad estatales y a las fuerzas armadas como principales perpetradores. Igualmente importante fue la aportación de estos informes para que otros gobiernos, organismos y actores no estatales pudiesen elaborar estrategias diplomáticas e incrementar su capacidad para ejercer presión sobre los regímenes represores de América Latina. ${ }^{25}$

De ahí que el legado de la represión brutal en América Latina no se limitara al registro minucioso de las atrocidades. Sin duda una de sus secuelas más importantes fue la propagación de nuevas aspiraciones normativas y el desarrollo de prácticas de investigación que no sólo permitieran garantizar la protección de los derechos humanos, sino llevar a la justicia a los responsables de los crímenes atroces. El veredicto de la Conadep sobre las "atrocidades sistemáticas" perpetradas por el gobierno militar argentino, que incluía la desaparición de 8960 personas y la existencia de 340 centros de detención clandestinos, las revelaciones del informe chileno de 1991 sobre cerca de 3000 asesinatos y desapariciones, así como su reconocimiento público de la imposibilidad de dar cuenta de la suerte de muchos aún ausentes, y el horror evidenciado por la Comisión para el Esclarecimiento Histórico de Guatemala, han sido fundamentales para hacer inteligible el pasado y

${ }^{25}$ En muchos de estos informes, la Comisión Interamericana de Derechos Humanos demandaba de manera constante que los perpetradores fueran juzgados y castigados. 
tratar de darle sentido. No es fácil discernir todas las consecuencias de estas investigaciones, pero de lo que sí tenemos certeza es de que las verdades atroces de los informes sobre Argentina y Chile, así como la evidencia sobre las campañas de exterminio y la violencia genocida en Guatemala que, en 36 años de conflictos internos, costó la vida a más de 200000 personas (la mayoría de ellas de origen maya, a saber, $83 \%$ de las víctimas), en su mayoría a manos de las fuerzas del Estado y grupos paramilitares, empujaron a las víctimas y a los activistas a romper el silencio y a asirse a la causa de los derechos humanos. ${ }^{26}$

${ }^{26}$ De igual importancia fueron los hallazgos de la Comisión de la Verdad y Reconciliación Nacional de Perú y de la más recientemente creada Comisión Nacional para la Verdad de Brasil. Tras tres años de trabajo, que incluyó audiencias e investigaciones in situ destinadas a evaluar el legado de veinte años de conflictos internos (1980-2000), la Comisión peruana pudo documentar más de 11500 casos de graves violaciones a los derechos humanos y ubicar cerca de 4600 fosas clandestinas en todo el país. Con base en 23969 casos reportados, la Comisión calculó el total de víctimas en 69280 personas. Aunque la Comisión identificó al grupo insurgente Sendero Luminoso como el "principal perpetrador de los crímenes y violaciones a los derechos humanos”, también atribuyó una grave responsabilidad a las agencias estatales y, más específicamente, al ejército. Al respecto, el informe concluyó que Sendero Luminoso era responsable de $54 \%$ de las muertes violentas; las fuerzas estatales de seguridad, de $37 \%$ (y cuando menos $61 \%$ de quienes morían a manos de las autoridades estatales eran también víctimas de desaparición forzada); el Movimiento Revolucionario Tupac Amaru (MRTA), de $2 \%$; y en el $7 \%$ restante se desconocía al ejecutor. Por su parte, con la consigna de investigar las graves violaciones a los derechos humanos en el periodo comprendido entre 1946 y 1988, el informe brasileño de 2014 identificó 377 individuos, casi 200 de ellos aún vivos, como responsables de los crímenes de lesa humanidad, incluidos tortura, asesinato y desaparición forzada. El informe documentaba el carácter sistemático de muchas de esas violaciones y el incremento del número total de víctimas, asesinadas o desaparecidas durante los años de la “Guerra Sucia”, de 362 a 434. Igualmente importante fue el veredicto de la Comisión sobre la intensidad de la cooperación regional para la represión autoritaria a todo lo largo del Cono Sur. Véase: Comissão Nacional da Verdade, en http:// www.cnv.gov.br/index.php/outros-destaques /574-conheca-e-acesse-o-relatorio-final-da-cnv; Human Rights Watch, "Brazil: Panel Details 'Dirty War' Atrocities. Truth Commission Identifies Abusers, Calls for Prosecutions”, 10 de diciembre de 2014, disponible en http://www.hrw.org/news/2014/12/10/brazil-panel-detailsdirty-war-atrocities; "Represión más allá de las fronteras. La Comisión de la Verdad de Brasil detalla los secuestros en el marco del Plan Cóndor", El País, 13 de 


\section{c) Las víctimas como arquitectos de los derechos humanos}

En la trayectoria de la contribución de América Latina al desarrollo y consolidación de las normas para la protección de los derechos humanos, incluidas las relativas al combate a la impunidad y a la RdeP, resaltan dos grandes relieves. Por un lado, la reactivación de las demandas de derechos humanos, incluida la demanda de justicia ante crímenes del pasado, no fue en modo alguna ajena a las violaciones graves y masivas de los derechos humanos que tuvieron lugar en varios países de la región. Por otro lado, la contribución de la región a la formulación de normas supranacionales de derechos humanos, así como a la criminalización de las atrocidades se desprende de una manera lógica de ese mismo pasado.

Sin duda, el rechazo generalizado a la represión brutal de los gobiernos militares en Chile y en Argentina actuó como catalizador para que se diera un cambio más amplio y profundo -de proporciones no sólo regionales, sino también internacionales-, en el que las dinámicas de las acciones dirigidas por los Estados y el activismo social compartieron a la vez un mismo escenario y se reforzaron mutuamente. De este modo, los esfuerzos épicos de los actores nacionales e internacionales para frenar las olas de violaciones y para intentar llevar a la justicia a miembros de los gobiernos autoritarios salientes desempeñaron un papel fundamental en la evolución normativa y práctica de los derechos humanos en la región. ${ }^{27}$

diciembre de 2014, disponible en http://internacional.elpais.com/internacional/ 2014/12/10/actualidad/1418234137_083738.html

${ }^{27}$ El juez Antonio Augusto Antônio A. Cançado Trindade ha reconocido explícitamente el papel desempeñado por las víctimas en la activación de los mecanismos e instituciones de derechos humanos. En su opinión, dado que la Comisión y la Corte no actúan ex officio en el sistema de peticiones, de hecho tienen que ser "provocadas" para pronunciarse sobre casos específicos. Al describir la determinación de víctimas, familiares y activistas resalta la conciencia que hoy existe sobre las posibilidades que puede brindar la jurisdicción internacional. Y concluye que el sistema inter-americano quizás no hubiese respondido de la misma manera a masacres y atrocidades como las que ocurrieron en Barrios Altos y la Cantuta en Perú en 2001, el caso de Myrna Mack Chang y la masacre Plan de Sánchez de 2004 en Guatemala o las masacres que tuvieron lugar en Colombia en Mapiripán, Ituango y Pueblo Bello. Véase Lauri R. Tanner, "Interview with Judge Antônio A. Cançado 
Es cierto que, en medio de las violentas crisis que sacudieron a estos países, los compromisos de derechos humanos que sus gobiernos habían contraído durante breves interludios democráticos fueron congelados. Pero, también lo es que en ausencia de esos compromisos los actores internos e internacionales no hubieran podido movilizarse para hacerlos valer. Las motivaciones inmediatas fueron tres: sacar a la luz las violaciones que estaban ocurriendo, denunciar y exhibir a los regímenes opresores y, en la medida de lo posible, limitar la magnitud de la represión. El registro de estas acciones puso en evidencia la relevancia de estas primeras obligaciones como plataforma para el despliegue de una movilización transnacional vigorosa en tiempos difíciles. De este modo, los activistas no sólo ayudaron a agitar el interés en círculos estadounidenses por las violaciones que estaban teniendo lugar en otras partes del continente, sino que dejarían ver su importancia como fuentes vitales de información para los debates que tendrían lugar en el Senado y en las audiencias de casos y países celebradas también en esos años en el Congreso. ${ }^{28}$ Tras el activismo desplegado por funcionarios, diplomáticos, personas y organismos incipientes de derechos humanos se gestaba un cambio significativo en la política internacional de los derechos humanos. En efecto, estos cambios sugerían que los gobiernos que incurrieran en violaciones graves a los derechos humanos podrían enfrentar costos elevados. En algunos casos, como el de Chile, los costos potenciales y reales terminaron por obligar al gobierno de Pinochet modificar y ajustar su conducta para apegarla a las líneas dictadas por los voceros de los derechos humanos. Estos desarrollos apuntalaron la idea de que en América Latina, como había ocurrido en Europa Occidental, el condicionamiento de la soberanía del Estado Nación, o incluso

Trindade, Inter-American Court of Human Rights", Human Rights Quarterly, vol. 31, núm. 4, noviembre de 2009, pp. 985-1005.

${ }^{28}$ Estas audiencias y debates resultaron muy ilustrativas tanto para los funcionarios de Estados Unidos como para los activistas sociales. Como lo han señalado Kathryn Sikkink y otros analistas, las intensas deliberaciones que tuvieron lugar durante esas audiencias prepararon el terreno para una dilucidación más compleja sobre los límites de la soberanía del Estado y contribuyeron a profesionalizar a las organizaciones de derechos humanos. Sikkink, op. cit., 2014, pp. 66-70. 
su reemplazo, en nombre de los derechos humanos, se había ya concretado. ${ }^{29}$

La confianza en la permanencia de los cambios políticos que habían tenido lugar desde principios de los años ochenta y hasta la primera mitad de los noventa llevó a su vez a reafirmar el compromiso de varios gobiernos con la agenda de derechos humanos. En muchos países, estos años estuvieron marcados por el derrocamiento de los regímenes de seguridad nacional y la gradual consolidación de la democracia. En América Latina, esta última ola democrática incrementó de manera muy importante el número de democracias electorales reconocidas y contribuyó a que los gobiernos regionales reafirmaran sus antiguos y nuevos compromisos con los derechos humanos. En muchos casos estos compromisos no sólo habían sido consagrados en instrumentos internacionales firmados y ratificados, sino que habían sido ya incorporados en los textos constitucionales. En algunos casos, habían incluso cristalizado en capacidades e instituciones embrionarias dedicadas a recabar, reunir y compartir información relativa a los derechos humanos. Aunque estas tendencias parecían sugerir que las normas de derechos humanos habían sido ya parcialmente internalizadas y, hasta cierto punto, regionalizadas, lo cierto es que su ejecución seguía obstaculizada por diversos factores. Desde el punto de vista interno, las instituciones militares siguieron detentando grandes prerrogativas y poderes fácticos, mientras que en el plano externo no se dio una transferencia real de autoridad de los Estados a los mecanismos e instituciones regionales de derechos humanos. Por consiguiente, en muchos casos, la ratificación de los instrumentos internacionales de derechos humanos no se tradujo de inmediato en una protección efectiva de estos derechos. Peor aún, la resistencia de las corporaciones militares y judiciales a las demandas de justicia y protección de derechos humanos encontró respuesta en perdones presidenciales y leyes de amnistía. Como era de esperarse, los niveles de cumplimiento de las obligaciones internacionales de derechos humanos observados en las jóvenes democracias latinoamericanas variaron en forma importante y siguieron mostrando

${ }^{29}$ Moyne, op. cit., p. 381. 
inconsistencias e irregularidades. No obstante las expectativas creadas por los procesos de democratización y de adhesión a instrumentos internacionales, en el terreno de indicadores suficientes $\mathrm{y} / \mathrm{o}$ precisos para medir el cumplimiento de las obligaciones de un Estado en materia de derechos humanos, no hubo grandes cambios.

El que la ejecución efectiva de estas obligaciones tomara tanto tiempo no se debió tan solo a la falta de voluntad política, sino también a las dificultades y restricciones que enfrentaron las jóvenes democracias latinoamericanas. Aunque nadie dudaba ya que los compromisos relativos a los derechos humanos habían llegado a formar parte intrínseca de las realidades regionales, lo cierto es que su puesta en práctica continuó siendo un objetivo difícil de alcanzar. Los gobiernos de las jóvenes democracias latinoamericanas pronto se vieron obligados a aceptar que las estructuras de incentivos para la ratificación y para la implementación no obedecían una misma lógica. La adhesión a y el cumplimiento de las normas de protección de los derechos humanos no dependían tan solo de la presencia de obligaciones legales. La implementación efectiva de estas obligaciones dependía de procesos complejos y del desarrollo de sistemas e infraestructura para su acatamiento. Al final, el cumplimiento de las obligaciones relativas a los derechos humanos dependía de una multiplicidad de factores, a veces de orden legal, en ocasiones de naturaleza política y, más a menudo, de factores complejos que involucraban a la vez lógicas internas y externas. ${ }^{30}$

Con todo y estas dificultades, a medida que la ola democrática avanzó, en algunos países la combinación de demandas internas y presiones externas y transnacionales ayudó a inclinar la balanza a favor de la causa de los derechos humanos. El problema inmediato fue que la disposición para cumplir con las normas internacionales dependió, en última instancia, de la capacidad de los actores estatales y no estatales para socializar y presionar a los Estados a que fortalecieran sus capacidades de promoción y protección de los derechos humanos, y a que erradicaran las prácticas represivas

${ }^{30} \mathrm{El}$ análisis de estos complejos sistemas de cumplimiento con frecuencia pone el énfasis en las organizaciones de derechos humanos y en la densidad de sus vínculos con la sociedad civil internacional. 
y desmantelaran los enclaves autoritarios. No debe, pues, extrañar que la evolución de la implementación de las normas de derechos humanos a nivel regional resultase de la interacción entre procesos de orden interno y la persuasión/coerción externa.

Es común ver en la transición y consolidación democráticas la explicación de los cambios observados en la política regional de derechos humanos. Poco hace falta para reconocer que el cambio democrático pudo haber dado lugar a un contexto favorable de respeto a los derechos humanos. Sin embargo, hoy por hoy, no existe un consenso claro sobre cuál pudo ser la contribución de la democratización a la protección real de los derechos humanos. ${ }^{31}$ Más aún, al igual que en el caso de la ratificación, la transición a la democracia no pareció ofrecer garantía alguna de que los derechos humanos serían efectivamente protegidos o de que los mecanismos de rendición de cuentas serían activados. No debe, pues, sorprender que tras la tercera ola democratizadora numerosas interrogantes continuaran acechando la calidad de los regímenes democráticos y su nivel de protección de los derechos humanos.

De hecho, lo que hemos visto en los procesos de transición y democratización es que la decisión de encarar los legados y enclaves autoritarios suele dar lugar a dos lógicas a la vez poderosas y opuestas: la de la impunidad y la de la supervivencia democrática. La trayectoria de las repúblicas latinoamericanas sugiere que las condiciones en las que la transición tiene lugar-un contexto autoritario o cargado de conflictos, una transición de naturaleza negociada o forzada, así como la distribución relativa del poder político durante y después de la transición-puede incidir no sólo en la

31 Véase entre otros Laurence Whitehead, "Democratization and Human Rights in the Americas”, en Louise Fawcett y Mónica Serrano (eds.), Regionalism and Governance in the Americas. Continental Drift, Basingstoke, Palgrave MacMillan, 2005, pp. 221-234; Manuel Antonio Garretón, "Human Rights in Processes of Democratization”, Journal of Latin American Studies, vol. 26, 1994, pp. 221-234; Joe Foweraker y Roman Krznaric, "The Uneven Performances of Third Wave Democracies: Electoral Politics and the Imperfect Rule of Law in Latin America”, Latin American Politics and Society, vol. 44, núm. 2, 2002, pp. 35-37; Joe Foweraker y Todd Landman, "Constitutional Design and Democratic Performance", Democratization, vol. 9, núm. 2, 2002, pp. 43-66. 
calidad de la vida democrática, sino también en las perspectivas de respeto a los derechos humanos. Aunque los distintos casos dejan ver las diversas rutas que los países tomaron en aras de reconciliar estas lógicas, el consenso incipiente (que contradice a una parte de los trabajos más tempranos e influyentes) apunta a que las transiciones seguirán siendo incompletas en tanto no se abatan los enclaves autoritarios y se aborden de manera efectiva los asuntos relativos a los derechos humanos.

Desde luego, la democratización y el compromiso con las normas internacionales, incluida la Corte Penal Internacional (CPI), abrieron nuevas oportunidades para que las organizaciones de derechos humanos continuaran presionando a sus gobiernos a cumplir sus compromisos de protección de los derechos humanos. A la vuelta del siglo, la presencia de comisiones e instituciones nacionales de derechos humanos y el apoyo de varios gobiernos latinoamericanos a la CPI parecía sugerir un mayor grado de convergencia en torno a los derechos humanos. Sin embargo, el escrutinio de los esfuerzos de implementación y aplicación de las normas sobre derechos humanos continuó arrojando enormes deficiencias. Como era de esperarse, un cambio de este calado no podía producirse de la noche a la mañana. A menudo, el peso de los legados y abusos del pasado obstaculizó los esfuerzos de consolidación democrática, mientras que la debilidad crónica de los mecanismos de rendición de cuentas continuó socavando la calidad de la vida democrática.

La variedad de caminos y secuencias observados en América Latina demostró que no existían procesos predeterminados y/o auto-impulsados para llegar a la protección efectiva de los derechos humanos y hacer justicia por los graves crímenes del pasado. Sin embargo, la experiencia latinoamericana también sugiere que las diferencias en los niveles de protección efectiva se deben, en buena medida, a las capacidades de los agentes domésticos para establecer sinergias con actores externos y potenciar de esta manera la coordinación entre los procesos internos y las lógicas externas. En algunos casos, los factores que empujaron las fronteras de la protección de los derechos humanos y la justicia por abusos del pasado fueron el resultado de dinámicas internas que impulsaron 
la activación de obligaciones previas de derechos humanos y/o empujaron al poder judicial a actuar. ${ }^{32}$ En esos casos, fueron procesos de abajo hacia arriba, apoyados por socios externos, pero con un claro predominio de actores locales y presiones generadas localmente, los que contribuyeron directamente a que se multiplicaran las demandas internas de respeto a la protección efectiva de los derechos humanos y de justicia por los crímenes cometidos. En otras experiencias, fueron procesos de arriba hacia abajo, estimulados por presiones internacionales, en buena medida asociadas a los cambios que estaban ocurriendo en el campo de la justicia penal internacional, los que influyeron en el surgimiento de electorados nacionales comprometidos con los derechos humanos. Desde esta perspectiva, ya sea que hubiesen sido activados interna o externamente, los derechos humanos y los reclamos de justicia fueron los catalizadores del desarrollo de una comunidad de derechos humanos más resiliente.

Estas tendencias sugerían importantes mutaciones en el paisaje de los derechos humanos $-y$, también, cada vez más, en el horizonte de la justicia- en América Latina. En algunos casos, la presencia de una competencia política y electoral más intensa no sólo alentó el surgimiento de instituciones estatales y no estatales de derechos humanos, sino la consolidación de derechos civiles y políticos. Éste fue definitivamente el caso de Argentina, un país que se ha distinguido por sentar precedentes y por su papel como "líder global" en materia de derechos humanos y justicia de transición. En Argentina, los temas sobre derechos humanos no sólo fueron incorporados a la dinámica de la democratización, sino que una y otra vez, gracias al despliegue de acciones creativas e innovadoras, el movimiento de derechos humanos pudo sortear numerosos obstáculos. En diferentes momentos, la interacción dinámica entre las medidas tomadas a nivel local y aquellas que se desplegaron en los ámbitos regional e internacional permitieron a Argentina ensanchar las fronteras de la protección de los

${ }^{32}$ Ezequiel González Ocantos, "Persuade Them or Oust Them: Crafting Judicial Change and Transitional Justice in Argentina", Comparative Politics, vol. 46, núm. 4, 2014, pp. 479-498. 
derechos humanos y de la rendición de cuentas por crímenes de lesa humanidad cometidos en el pasado. Gracias al esfuerzo incesante de organizaciones y activistas comprometidos con la ampliación de las fronteras de los derechos humanos en Argentina, pudieron darse las condiciones para la consolidación de una democracia abiertamente comprometida con el respeto a los derechos humanos. ${ }^{33}$ De manera similar, las innumerables trabas que el régimen militar de Pinochet buscó imponer a la transición democrática y a la situación de los derechos humanos en Chile fueron una y otra vez enfrentadas por los actores y fuerzas en favor de los derechos humanos y la justicia. Gracias a estos esfuerzos, cerca de 500 miembros activos o antiguos miembros del ejército y la política fueron sentenciados y el propio general Pinochet fue procesado por cargos de lavado de dinero. ${ }^{34}$ En Perú, la trascendencia de la rendición de cuentas en materia de derechos humanos ha sido también evidente. Conviene mencionar, por ejemplo, el trabajo de la Comisión de la Verdad y Reconciliación Nacional, así como los procesos judiciales por violaciones serias a los derechos humanos, tales como la extradición y juicio del expresidente Alberto Fujimori por crímenes de lesa humanidad. ${ }^{35}$

Es claro que la importancia de estas tendencias no radica en los casos individuales, sino en el hecho de que, en conjunto, contribuyeron a que se legalizaran las normas supranacionales y se criminalizaran los actos de lesa humanidad. Aunque lejos de ser perfecta, la necesidad de reconciliarse con el pasado se manifestó de manera vívida a lo largo y ancho del continente americano en

${ }^{33}$ Smulovitz, “'The Past Is Never Dead': Accountability and Justice for Past Human Rights Violations in Argentina”.

${ }^{34}$ Human Rights Watch, "When Tyrants Tremble: The Pinochet Case in Chile”, Octubre de 1999; Naomi Roth-Arraiza, The Pinochet Effect: Transitional Justice in the Age of Human Rights, Filadelfia, University of Pennsylvania, 2005; Claudio Fuentes, "The Unlikely Outcome: Transitional Justice in Chile 1990-2008”, en Mónica Serrano y Vesselin Popovski (eds.), After Oppression: Transitional Justice in Latin America and Eastern Europe, Tokio, United Nations University Press, 2012.

${ }^{35}$ Jo-Marie Burt, "Guilty as Charged: The Trial of Former Peruvian President Alberto Fujimori for Human Rights Violations", International Journal of Transitional Justice, vol. 3, núm. 3, 2009, pp. 384-405. 
la proliferación de comisiones de la verdad e instituciones nacionales de derechos humanos. Más aún, la sed de justicia se tradujo, por un lado, en la práctica revolucionaria de activar tribunales en terceros países, ya fuese en España, Francia o Italia, para resolver los casos de lesa humanidad cometidos en América Latina, y por el otro en acciones sin precedentes para reposicionar al poder judicial como el vehículo privilegiado de justicia para casos de crímenes contra la humanidad. ${ }^{36}$ Siguiendo estos diversos caminos, los activistas, las víctimas y sus abogados propiciaron el conocimiento y difusión de las leyes regionales e internacionales sobre derechos humanos y se lanzaron de lleno en la ardua e insoslayable tarea de demoler los enclaves de la impunidad.

La forma en que los países latinoamericanos manejaron la tensión entre el gobierno democrático y la protección a los derechos humanos y rendición de cuentas por violaciones cometidas en el pasado contribuiría a definir el carácter de las democracias en América Latina. La relación entre rendición de cuentas y gobierno democrático, así como entre justicia de transición y Estado de derecho, pronto atrajo la atención de estudiosos en el continente. Más

36 González Ocantos (art. cit.) sostiene que el éxito comparativo de los actores de derechos humanos en Argentina, pero también los límites que presentó la revolución de la justicia en ese país, pueden explicarse a partir de las "microdinámicas de difusión de las normas". Estas dinámicas permitieron que los jueces se socializaran en las leyes y conceptos de los derechos humanos, lo cual contribuyó a que sectores importantes del Poder Judicial se transformaran en plataformas de justicia pro-transicionales. El análisis de Ocanto revela cómo al basarse en el derecho a la verdad de las víctimas -como parte de las investigaciones no penales-jueces pioneros pudieron solicitar la presencia de los presuntos perpetradores. En poco tiempo, para mediados de la década de 1990, este método dio lugar a una avalancha de juicios de derecho a la verdad. En el caso de los niños secuestrados, los jueces pudieron proceder por cargos relacionados con el secuestro, pero no se les permitió que acusaran a los funcionarios por desaparecer a los padres. Los jueces que querían sumarse a la causa de los derechos humanos debían navegar por las pantanosas aguas de una cultura legal formalista y positivista y, en ese sentido, las alianzas establecidas con los organismos de derechos humanos fueron cruciales. Una vez que un caso llegaba a la corte, los activistas, armados con argumentos legales innovadores, empezaron a interponer recursos interlocutorios por violaciones graves a los derechos humanos. González Ocantos, "Persuade Them or Oust Them". 
allá de la preocupación por el tema de la impunidad, ante el fracaso de las reformas institucionales y de las acciones para la rendición de cuentas, diversas voces advirtieron del riesgo de una regresión autoritaria. Otros apuntaron a la relación entre el Estado de derecho y la procuración de justicia por las violaciones a los derechos humanos, señalando las muchas formas en las que éstos interactúan y se refuerzan mutuamente en la práctica. En su opinión, la rendición de cuentas está intrínsecamente ligada a la evolución del Estado de derecho, por lo que fallar en eso pondría en jaque la capacidad del país para hacer valer el Estado de derecho. ${ }^{37}$

Estas realidades complejas encontraron expresión en Perú y Brasil. En el primer caso, las irregularidades electorales que enturbiaron la tercera elección disputada del equipo Fujimori-Montesinos coincidieron con el incumplimiento manifiesto por parte del país de dos sentencias clave de la CidH. ${ }^{38}$ Mientras tanto, en Brasil, el peso político de actores militares e intereses conservadores creó las condiciones para que, durante mucho tiempo, los actores autoritarios siguieran dictando los términos y el alcance de la protección de los derechos humanos, de la justicia de transición y de la vigencia de la Ley de Amnistía de 1979 (Ley 6683/79). Pero aún en Brasil, para diciembre de 2010 el equilibrio entre impunidad y derechos humanos comenzó a cambiar. Primero fue el fallo de la Corte Interamericana de Derechos Humanos, que impugnó el estatus legal de la Ley de Amnistía y refutó abiertamente una sentencia del Tribunal Supremo que poco antes había ratificado la validez de dicha ley. Envalentonado por estos acontecimientos, el recién electo gobierno de Dilma Rousseff comenzó a impugnar la impunidad militar. En septiembre de 2011, el Congreso de Brasil aprobó los planes para la creación de una Comisión de

${ }^{37}$ Pilar Domingo, “Accountability: The Rule of Law and Transitional Justice in Latin America”, en Mónica Serrano y Vesselin Popovski (eds.), After Opression: Transitional Justice in Latin America and Eastern Europe, Tokio, United Nations University Press, 2012, pp. 41-63.

${ }^{38}$ Fue necesario que el juez Antônio A. Cancado Trinidade tomara una acción decidida y que la oEA implementara con energía estándares electorales democráticos para que en Perú las estrellas de los derechos humanos y la democracia se alinearan de manera inusualmente clara. 
la Verdad. Simbolizando el papel de víctima de violaciones de derechos humanos y tortura, la presidenta Dilma Rousseff estableció la Comisión en 2012 para que investigara las violaciones sistemáticas de derechos humanos ocurridas durante el régimen militar y, poco después, en el verano de 2013, supervisó la creación de Sistema Nacional para Prevenir y Combatir la Tortura.

Ya fuera como resultado de los cambios en el entorno político y en la correlación de fuerzas entre las corrientes democráticas y autoritarias, o de la determinación de funcionarios comprometidos con las reformas democráticas y de derechos humanos, del impacto de una política exterior de derechos humanos resuelta a denunciar a los represores, del surgimiento de la justicia penal internacional, de la fuerza del activismo transnacional o de la perseverancia que mostraron los jueces y fiscales para desmantelar los regímenes de impunidad, lo cierto es que en América Latina el cambio de siglo se vio marcado por un viraje hacia la legalización de las normas y prácticas supranacionales que condicionaban la soberanía del Estado al respeto a los derechos humanos.

Aunque este proceso ha sido lento y doloroso, los cambios que tuvieron lugar en la región dejaron ver que el retorno al Estado de terror no sería fácil. La verdadera dimensión de estos cambios se hizo particularmente evidente en la propensión de las víctimas y sus abogados a recurrir a la normativa internacional de derechos humanos y en los efectos que la ejecución a nivel nacional, regional e internacional de esas normas tuvo sobre las políticas y los funcionarios estatales. Apenas unos años antes, era impensable pensar que en 1998 estos cambios allanarían el camino para el arresto y solicitud de extradición del general Pinochet en Londres por graves cargos de violaciones a los derechos humanos. O que la primera extradición en la historia de un exmandatario por crímenes de lesa humanidad podría ocurrir entre dos países de la región. En efecto, en septiembre de 2007, la Suprema Corte de Chile aprobó la extradición del expresidente de Perú, Alberto Fujimori, por cargos de violación de derechos humanos y corrupción. ${ }^{39}$ Dos años

${ }^{39}$ Fujimori fue extraditado con base en dos cargos de violación de derechos humanos y cinco de corrupción. "Extradited Fujimori back in Peru", BBC News, 22 
después, en diciembre de 2009, la Suprema Corte de Perú, con base en el concepto de "autoría mediata" y el control que el mandatario ejercía sobre una unidad militar, le fincó responsabilidades por violaciones graves a los derechos humanos, sentenciándolo a 25 años de prisión. Durante su evaluación de las evidencias, la Corte identificó un patrón de violaciones sistemáticas a los derechos humanos y, con base en la jurisprudencia regional e internacional, definió éstas violaciones como "crímenes de lesa humanidad". ${ }^{40}$

Es cierto que el horizonte latinoamericano permaneció bajo la penumbra de enormes deficiencias de derechos humanos. Como ningún otro caso, Guatemala ejemplificó el abismo que perdura en la región entre la voluntad política de adherirse a los instrumentos para proteger los derechos humanos y la capacidad de ponerlos efectivamente en práctica. Con todo, esta brecha entre discurso y práctica no obsta para que se pueda rastrear la apertura hacia la RdeP en buena parte de los cambios observados en el ámbito de los derechos humanos y la rendición de cuentas. Una señal temprana de esta apertura fue la respuesta de los Estados de la región a la intervención de la OTAN en Kosovo, en 1999, y los debates que le siguieron en torno a la legalidad y legitimidad del uso de la fuerza.

\section{AMÉRICA LATINA Y LA RESPONSABILIDAD DE PROTEGER}

A lo largo de la década de 1990, no sólo los avances logrados en el campo de los derechos humanos, sino también la dimensión regional de la democratización y la integración, allanaron el camino a una concepción más flexible de la soberanía y la no intervención. En primer lugar, las definiciones absolutas de soberanía empezaron a ser cuestionadas ante el papel que desempeñaron la onU, la

de septiembre de 2007 disponible en http:/ / news.bbc.co.uk/2/hi/7008302.stm; Simón, Romero, "Court approves extradition of Fujimori", New York Times, 21 de septiembre de 2007, disponible enhttp:/ /www.nytimes.com/2007/09/21/world/ americas /22chile.html?fta=y\&_r=0.

${ }^{40}$ Jo-Marie Burt, "Guilty as Charged: The Trial of Former Peruvian President Alberto Fujimori for Human Rights Violations", The International Journal of Transitional Justice, vol. 3, núm. 3, 2009, p. 398. 
oEA y la Unión Europea en los procesos de pacificación y construcción de gobiernos democráticos en Centroamérica. Igualmente importante fue la tendencia regional normativa que dio por resultado el Compromiso de Santiago con la Democracia y la Renovación del Sistema Interamericano, en 1991. El acuerdo fue firmado por los Estados de la región durante la XXI Asamblea General de la oea que tuvo lugar en junio de ese año, en Santiago de Chile, comprometiendo a las partes a defender y promover la democracia representativa y los derechos humanos. Si bien es cierto que la idea inicial era que dicho compromiso operaría en el marco de los principios de autodeterminación y no intervención, al suscribir la resolución 1080 los Estados regionales activaron un mecanismo para intervenir colectivamente en el caso de que un régimen democrático colapsara. ${ }^{41}$ Más aún, tanto la práctica desarrollada por la oEA en una cadena de crisis, cuyo rasgo característico fue la amenaza potencial al proceso democrático, como la adopción en septiembre de 2001 de la Carta Democrática Interamericana darían forma a una nueva doctrina interamericana de gobierno democrático. ${ }^{42}$ Esto no significaba que los temores de intervención hubieran cedido del todo -de hecho, varios países, entre ellos Brasil y México, expresaron su inquietud a través de diversos canales-, o que los países de la región dieran su anuencia para que el principio de gobernanza democrática se extendiera a la protección colectiva de los

41 Este mecanismo para responder a interrupciones anticonstitucionales del régimen democrático recibió un segundo impulso cuando en 1992 se adoptó el Protocolo de Washington, el cual otorgó a la oEA facultades para suspender a todo Estado miembro cuyo gobierno e instituciones políticas sean tomados mediante el uso de la fuerza. El texto original del Compromiso de Santiago y de la AG/RES. 1080 (XXI-O/91), adoptados el 4 de junios de 1991 se encuentran en http:/ /scm.oas.org/pdfs/agres/ag03805S01.PDF Véase también Heraldo Muñoz, "The oAs and Democratic Governance", Journal of Democracy, vol. 4, núm. 3, julio de 1993, pp. 29-38.

42 Bajo este mandato, la oeA intervino en Haití en 1991 y ayudó a restaurar el régimen democrático en Perú en 1992; en Guatemala, en 1993; y en Paraguay, en 1996. La Carta Democrática se encuentra en http:/ /www.oas.org/OASpage/esp/ Documentos/Carta_Democratica.htm Asimismo, véase Thomas M. Frank, "The Emerging Right to Democratic Governance", American Journal of International Law, vol. 86, núm. 1, enero de 1992, pp. 46-91. 
derechos humanos, pero sí apuntaba a una mayor convergencia hacia una soberanía limitada y condicionada. ${ }^{43} \mathrm{~A}$ medida que aparecieron principios democráticos y cláusulas de condicionalidad en las iniciativas regionales -del Grupo de Río al Mercosur, al Tratado Marco de Seguridad Democrática en Centroamérica-, se hizo visible una incipiente práctica regional de apoyo colectivo al gobierno democrático y a la soberanía condicionada. ${ }^{44}$ Estas tendencias, junto con la expansión de las demandas y avances en materia de derechos humanos que surcaron la región, prepararon el terreno para que América Latina respondiera en la forma como lo hizo a la crisis de Kosovo y al informe de la Comisión Internacional sobre Intervención y Soberanía Estatal sobre la Responsabilidad de Proteger de 2001.

Hubo, por supuesto, diferencias importantes entre los países latinoamericanos en su respuesta colectiva o individual a la crisis de Kosovo y a la intervención de la OTAN. Las divergencias considerables que entonces pudieron observarse entre la posición de países como Argentina y Chile, y en menor grado Brasil -que apuntaba a conciliar soberanía y respeto a los derechos humanos- y México que en ese momento privilegiaba claramente la primera sobre los derechos humanos-, se derivaban de la naturaleza de sus regímenes, sus procesos de democratización y su vulnerabilidad a la presión internacional asociada a derechos humanos. Con diversos argumentos se ha buscado explicar el apoyo de México a la soberanía incondicional y su objeción general a la intervención humanitaria de la otan en Kosovo. Desde luego, el hecho de que México

${ }^{43}$ De hecho, el principio de gobernanza democrática fue parte de una interpretación bastante estrecha y básicamente electoral de la democracia. Más aún, la oleada de apoyo a los procesos electorales estuvo claramente vinculada a un cambio drástico en la política de Estados Unidos hacia la región durante los años de Reagan y que llevó a un giro de la promoción de los derechos humanos a la promoción de la democracia. Véase Thomas Carothers, "The Resurgence of US Political Development Assistance to Latin America in the 1980s", en Laurence Whitehead (ed.), The International Dimensions of Democratization: Europe and the Americas, Oxford, Oxford University Press, 2001.

${ }^{44}$ Andrew Hurrell, "An Emerging Security Community in South America”, en Emmanuel Adler y Michael Barnett (eds.), Security Communities, Cambridge, Cambridge University Press, 1998, pp. 228-264. 
perdiera la mitad de su territorio frente a Estados Unidos fue un factor histórico que determinó la postura no intervencionista del país desde tiempo atrás. Otro factor fue el carácter autoritario del régimen priista y su respuesta defensiva a las demandas de democratización y, por último, pero no menos importante, la exclusión por mucho tiempo de los gobiernos del PRI de las presiones por violaciones a los derechos humanos. ${ }^{45}$ Es cierto que en el contexto de la operación de la oTAN en Kosovo muchos países objetaron la falta de autorización del Consejo de Seguridad de la onU y el enfoque selectivo a la intervención, pero a su vez es cierto que el argumento sobre la obligación colectiva de responder ante crímenes internacionales y violaciones a la legislación internacional humanitaria también ganó adeptos en la región. Tomando en consideración todas las diferencias y visiones encontradas, la declaración que emitió el Grupo de Río el 25 de marzo de 1999 planteó una solución basada por igual en el respeto a los derechos humanos y a la soberanía. De esta forma, aunque lejos de ser unánime, la respuesta de América Latina a la intervención militar de la OTAN en la antigua Yugoslavia pareció sumarse a la opinión internacional, que entonces concluía que, aunque ilegal, la acción de la отAN había sido perfectamente legítima. ${ }^{46}$

La lógica de estos cambios y de la presencia de una comunidad regional de derechos humanos cada vez más vigorosa puede apreciarse mejor en el papel que desempeñaron los países latinoamericanos en el complejo proceso de negociación para que se incluyera la RdeP en los párrafos 138 y 139 del Documento Final de la Cumbre Mundial de 2005. No obstante, al analizar la participación de la región en los debates e iniciativas políticas en torno a la RdeP del periodo 2005-2015, se observan importantes diferencias de opinión. Los países estaban y siguen estando divididos en un espectro

45 Diego Dewar y Mónica Serrano "México y la Responsabilidad de Proteger" en Guadalupe González G, Olga Pellicer y Natalia Saltalamacchia (eds.), México y el Multilateralismo del siglo XXI, México, Siglo XXI Editores, 2015, pp. 170-206.

${ }^{46}$ Mónica Serrano, "Latin America: The Dilemmas of Intervention", en Albrecht Schnabel y Ramesh Thakur (eds.), Kosovo and the Challenge of Humanitarian Intervention: Selective Indignation, Collective Action and International Citizenship, Tokio, United Nations University Press, 2000, pp. 223-244. 
en el que, en un extremo, se encuentra un grupo importante de países -entre los que destacan Argentina, Chile, Costa Rica, Guatemala, México y Uruguay- que ha dejado ver su simpatía hacia la RdeP y, en el otro, un grupo pequeño pero cohesionado de oponentes. El apoyo de los países que se encuentran en el primer grupo ha estado asociado a dos argumentos: por un lado, a las lecciones derivadas de la experiencia y legado de crímenes de lesa humanidad y, por otro, a las ventajas potenciales que estos países perciben en una apuesta de intervención regulada por el marco multilateral de la ONU. En contraste, los oponentes, que incluyen a Cuba, Nicaragua y Venezuela, siguen viendo a la RdeP como el caballo de Troya de los intereses imperialistas. Mientras que el primer grupo participa activamente en la red informal que integra el "Grupo de Amigos de la Responsabilidad de Proteger”, el segundo ha cuestionado y resistido enérgicamente los esfuerzos para desarrollar y consolidar el principio. Es cierto que muchos países latinoamericanos, incluidos los que están a favor del principio, han expresado su inquietud con respecto a los peligros que entraña el uso de la fuerza, el peligro de selectividad y las implicaciones de confiar la legitimidad de la RdeP a un órgano tan controvertido como es el Consejo de Seguridad. Pero, en términos generales, las naciones de América Latina han admitido que, con demasiada frecuencia, la onu y la comunidad internacional de Estados miembros han eludido la responsabilidad de prevenir y responder a los crímenes de lesa humanidad. Debido a ello, varias repúblicas latinoamericanas vieron con buenos ojos el espíritu preventivo de la RdeP y han reconocido la necesidad de llegar a un acuerdo respecto de los procedimientos y mecanismos institucionales para responder a los crímenes atroces. Pero, si bien la RdeP ha obtenido el apoyo moderado de un número importante de países latinoamericanos, no ha logrado avance alguno entre sus oponentes.

Lo cierto es que esta división, aparentemente irreconciliable, entre dos grupos de países latinoamericanos no fue suficiente para apartar a la región de los esfuerzos tendientes a desarrollar la RdeP. De hecho, para muchos países de América Latina la mutación del principio hacia los derechos humanos y los crímenes de lesa humanidad y de guerra representó una propuesta muy atractiva. De ahí 
que varios países latinoamericanos consideraran la versión de 2005 de la RdeP como el mejor camino para prevenir los crímenes de lesa humanidad. Una vez que el principio fue redefinido en términos de "genocidio, crímenes de guerra, crímenes contra la humanidad y limpieza étnica”, su alcance fue confinado a los parámetros establecidos por dichos delitos y se resolvieron, también, las inquietudes que había suscitado la apuesta de la intervención humanitaria. Gracias a estos desarrollos, la RdeP pudo ganar adeptos entre países de la región y de fuera. Más aún, para muchos países latinoamericanos la terminología que la RdeP adoptó en 2005 no sólo redujo el alcance del principio, sino que en esencia reafirmó muchos de los compromisos y obligaciones internacionales que estos países ya habían contraído. En efecto, dado que la definición de 2005 de la RdeP está basada en la legislación internacional existente, no hizo sino reiterar muchas de las obligaciones con las que ya se habían comprometido muchos Estados de América Latina. ${ }^{47}$

La voluntad de varios países latinoamericanos de suscribir la responsabilidad de proteger no podría explicarse si no se considerara el papel que hoy desempeñan los derechos humanos tanto en el ámbito doméstico como a nivel regional. En el plano nacional, los compromisos en materia de derechos humanos no sólo se expresaron en una proliferación de ombudsmen y comisiones nacionales de derechos humanos, sino también en electorados comprometidos con el tema. Sin duda una de las evidencias más contundentes de la importancia que han adquirido los derechos humanos en la región podemos rastrearla en la simpatía y apoyo que los países latinoamericanos mostraron desde un inicio hacia el proyecto de la CPI. ${ }^{48} \mathrm{En}$

47 UN Secretary-General's Report, Implementing the Responsibility to Protect, 2009 A/63/677, disponible en http://www.un.org/en/ga/search/view_doc.asp?symbol$=\mathrm{A} / 63 / 677$

48 Véase, entre otros, Don Hubert, "The Landmine Ban: A Case Study in $\mathrm{Hu}$ manitarian Advocacy", con un prefacio de S. Neil MacFarlane, Providence, The Thomas J. Watson Jr. Institute for International Studies, Brown University, 2000, 93 pp. (Occasional Papers, 42), disponible en: http:/ /www.watsoninstitute.org/pub/ op42.pdf; Richard J. Goldstone, "The Role of the ICC", en Robert I. Rotberg (ed.), Mass Atrocity Crimes: Preventing Future Outrages, Washington, D. C., Brookings Institution Press, 2010, pp. 55-68. 
efecto, tanto los países que han dado su voto incondicional a la RdeP, como aquellos que han aceptado el espíritu de la prevención pero que han rechazado el recurso al uso de la fuerza para prevenir crímenes atroces (pilar tres de la RdeP), e incluso los oponentes de la RdeP, firmaron y ratificaron el Estatuto de Roma. ${ }^{49}$

$\mathrm{Al}$ igual que en el caso de los derechos humanos, la inclinación a apoyar los tres pilares de la RdeP, o a acotar este apoyo a los pilares preventivos, parece estar asociada a diversos factores, pero, ante todo, a la naturaleza particular de la transición a la democracia y al legado de crímenes de lesa humanidad de cada país. De esta forma, aunque Argentina, Chile, Costa Rica, Guatemala, México y Uruguay son todos miembros del Grupo informal de Amigos de la RdeP y que, salvo por el caso de México, han avanzado en la institucionalización interna de la RdeP, designando a un funcionario responsable de sentar los cimientos para una oficina nacional, la posición de estos países hacia la RdeP aún muestra variaciones importantes.

Como ocurre en el plano más amplio de los derechos humanos, en el terreno de la RdeP también pesan las trayectorias de democratización, las experiencias particulares de violaciones graves de derechos humanos, así como los retos que estos países enfrentan en esa materia. De este modo, ya sea en sus contribuciones ante crisis específicas o en sus intervenciones en los debates que han tenido lugar sobre la RdeP, Argentina, Chile y Uruguay han sido consistentes en su respaldado a un principio que reivindica la obligación de los Estados de proteger los derechos humanos de las poblaciones, cuya responsabilidad trasciende las fronteras de los Estados y que los conmina a participar en acciones oportunas y decididas, pero sujetas a la aprobación multilateral de la onU vía el Consejo de Seguridad. Al explicar su apertura hacia la RdeP, Argentina ha subrayado, por ejemplo, el papel activo que desempeñó en la redacción del

${ }^{49}$ Argentina, Belice, Bolivia, Brasil, Colombia, Costa Rica, Ecuador, Guatemala, Honduras, México, Panamá, Paraguay, Perú, Uruguay y Venezuela, junto con otros nueve países del Caribe forman ahora parte del Estatuto de Roma. Las fechas en las que los Estados ratificaron el Estatuto se hallan en http://www.icc-cpi. int/en_menus/asp/states\%20parties/Pages/the\%20states\%20parties\%20to\%20 the $\% 20$ rome $\% 20$ statute.aspx 
Estatuto de Roma y en la creación de la CPI y, junto con Uruguay, ha llamado la atención a la importancia de los mecanismos de justicia de transición en los esfuerzos para evitar crímenes de lesa humanidad. Asimismo, Argentina y Uruguay han resaltado su contribución a los esfuerzos previstos por el segundo pilar de la RdeP que alude a la cooperación internacional para prevenir crímenes atroces. Y, si bien la mayoría de estos países había ya aceptado la promoción de los derechos humanos como meta integral de su política exterior, Chile y Costa Rica han incorporaron ya a la RdeP entre sus prioridades de política exterior. En efecto, las cadenas internas que durante años sujetaron el proceso de democratización en Chile tuvieron consecuencias decisivas en la política exterior chilena. No es una coincidencia que la política exterior chilena haya enarbolado explícitamente su compromiso con el fortalecimiento de los derechos humanos y de la vida democracia en el país y en la región. Si bien sustentada en la necesidad de rehabilitar la reputación internacional de Chile, la aprobación temprana y ágil de los instrumentos de derechos humanos por una coalición de centro-izquierda, de la que formaban parte víctimas de la represión del Estado, tenía la intención de precipitar cambios internos que contribuyeran a consolidar la democracia y el respeto a los derechos humanos. El apoyo de Chile tanto a la CPI como a la RdeP fue una derivación natural del enfoque de esa política. Pero donde el peso de los derechos humanos, incluida la RdeP, aparece con más claridad que en ningún otro lado es quizás en la política exterior de Costa Rica. El apoyo de este país a la RdeP ha sido totalmente congruente con el lugar destacado que siempre han tenido los derechos humanos en la política exterior costarricense. Desde los primeros años de la posguerra, esta nación centroamericana expresó su inquietud con respecto a las implicaciones que tenía el concepto de soberanía en los casos de regímenes despóticos que abusaban de sus poblaciones y, a raíz de la crisis de Bosnia, mostró su disposición a apoyar casos específicos de intervención militar que estuvieran encaminados a ayudar a las víctimas. Basándose en el principio de que la obligación de proteger los derechos humanos fundamentales es superior a las pretensiones de soberanía, Costa Rica se unió a los gobiernos de Dinamarca y Ghana en 
sus afanes para crear las oficinas nacionales o Puntos Focales sobre RdeP. La solidez de sus instituciones democráticas, sus antecedentes en cuanto a actividades internacionales y relativas a derechos humanos, así como sus muchos años como sede de la Corte Interamericana de Derechos Humanos hicieron de Costa Rica un candidato particularmente viable para encabezar esta iniciativa. En mayo de 2011, junto con Dinamarca y Ghana, Costa Rica convocó a la primera reunión de Puntos Focales Nacionales sobre RdeP. ${ }^{50}$

Si Argentina, Costa Rica, Chile, Guatemala y México representan el ala más favorable a la RdeP, bajo el liderazgo de Brasil, los partidarios moderados de la RdeP han insistido en tres condiciones básicas que todo proyecto de prevención de crímenes contra la humanidad debería cumplir. En primer lugar, subrayan la primacía que debe tener la prevención sobre la protección; segundo, la relación entre desarrollo sustentable, inclusión social y prevención de conflictos y crímenes de lesa humanidad; y, tercero, la preponderancia del consenso en torno al tema de la coerción como base de las respuestas. Aunque Bolivia, Brasil, Ecuador y Perú no han objetado la necesidad de evitar y responder ante los crímenes atroces, su postura difiere claramente de la que sostienen los países que han dado su aval a la RdeP. Ante todo, sus participaciones, ya sea en los debates en torno a la RdeP, o en las crisis en las que la RdeP ha sido invocada, revelan que las violaciones a los derechos humanos suelen ser percibidas como resultado de condiciones estructurales, más que como comportamientos ideológicos y opresivos. Brasil, lo mismo que Bolivia, Ecuador y Perú, desde hace mucho tiempo ha insistido en que el subdesarrollo y la falta de oportunidades económicas pueden ser detonadores de conflictos y de crímenes contra la humanidad. De ahí que Itamaraty haya optado por privilegiar los

${ }^{50}$ Desde el principio, el Centro Global para la Responsabilidad de Proteger (GCR2P por su nombre en inglés) quiso incluir a Costa Rica en el grupo nuclear de países que encabezarían la iniciativa, junto con un candidato de Asia. Véase "Meeting of National Focal Points on R2P convened by Costa Rica, Denmark and Ghana, New York, 17 and 18 May 2011”, GCR2P, junio de 2011, disponible en http:/ / www.globalr2p.org/media/files / meeting-of-national-focal-points-of-r2pconvened-by.pdf 
esfuerzos de prevención que reconocen los factores que están en la raíz de esos fenómenos. Además, el liderazgo político de estos países ha descansado en una narrativa que destaca la necesidad de seguir desarrollando y afinando las dimensiones conceptuales y prácticas de la RdeP. En opinión de estos países, la RdeP no debe socavar, sino fortalecer la soberanía y la mejor forma de lograrlo es con medios no coercitivos. La única excepción parcial a esto serían las intervenciones de RdeP realizadas con éxito a través de la onU, más que por medio de coaliciones de adeptos y voluntarios. Pese a ello, desde la intervención en Libia, en 2011, el blanco de las críticas ha sido la implementación responsable de la RdeP. Mientras que para algunos el llamado de Brasil a la "Responsabilidad durante la Protección" constituye una perspectiva constructiva para la implementación de la RdeP, otros han señalado sus posibles implicaciones perjudiciales para los procesos de toma de decisiones en el Consejo de Seguridad.

A la cabeza de las acciones para hacer fracasar el primer diálogo interactivo de la Asamblea General sobre Responsabilidad de Proteger, Nicaragua, junto con Cuba y Venezuela insistieron en la visión de una soberanía general y objetaron el principio en términos casi absolutos. Para estos países -dos de los cuales fueron blanco de fuertes acometidas intervencionistas de Estados Unidos en el siglo xx, pero también territorios inmunes al efecto de los vientos de la democratización y los derechos humanos-, la RdeP esconde designios hegemónicos e imperialistas. Si bien durante sus intervenciones en los debates sobre RdeP, Cuba, Nicaragua y Venezuela han condenado los crímenes atroces, también han llamado la atención sobre cómo la RdeP puede ser utilizada para violar la legislación internacional, la Carta de Naciones Unidas, la soberanía estatal y la autodeterminación. Aunque de diferentes formas, los tres países han cuestionado la base legal sobre la que se invoca la RdeP y que se usa para justificar decisiones que han llevado a intervenciones y cambio de regímenes por medio de coerción. 
A MANERA DE CONCLUSIÓN

¿Dónde queda, entonces, la responsabilidad de proteger en América Latina? Sería fácil concluir en un tono positivo, señalando los notables logros que ha tenido la comunidad de derechos humanos en América Latina, o haciendo alusión a la alentadora respuesta de varios países latinoamericanos al proyecto de la RdeP. Después de todo, las violaciones que describía García Márquez en 1982 que fueron la nota desventurada de los gobiernos autoritarios y dictaduras militares que dominaron a la región en esos años han sido atajadas y en algunos casos, como quizás en Argentina, incluso erradicadas, gracias al trabajo incansable de muchos actores en varios frentes. Los esfuerzos de víctimas, familiares, activistas y funcionarios comprometidos con los derechos humanos abarcan desde ambiciosas iniciativas legislativas para acotar las funciones de las fuerzas armadas al ámbito de la defensa externa, planes de reforma del sector de seguridad, una multitud de esfuerzos de derechos humanos de alcance nacional, regional e internacional y desde luego las medidas pioneras en el campo de la justicia de transición.

El logro de estos esfuerzos incansables no obsta para reconocer los enormes desafíos de derechos humanos que hoy penden sobre la región. Quienes en el pasado reciente celebramos los frutos del trabajo decidido y valiente de activistas y organizaciones de derechos humanos hoy vemos con profunda preocupación el rumbo que han tomado los derechos humanos en muchos países latinoamericanos. En efecto, justo cuando esta región era reconocida por organizaciones y expertos en derechos humanos por su experiencia y prácticas en protección de derechos humanos, por haber abierto brecha con una de las jurisprudencias más avanzadas en crímenes de lesa humanidad y por su liderazgo en justicia de transición, con cerca del 55\% de los casos desahogados en cortes nacionales a nivel mundial, el continente comenzó a perfilarse como una de las zonas más violentas del mundo. ${ }^{51}$

51 Kathryn Sikkink, The Justice Cascade: How Human Rights Prosecutions Are Changing World Politics, Nueva York y Londres, W. W. Norton \& Company, 2011, pp. 22-23. 
Hoy encontramos que con sólo $8.5 \%$ de la población mundial América Latina concentra $36 \%$ de la tasa mundial de homicidios. No sólo $20 \%$ de los países más violentos del mundo se encuentran en esta región, sino que entre los años 2000 y 2010 la tasa de homicidios en América Latina aumentó $11 \%, 52$ cifra que contrasta con las tendencias a la baja que se observaron en ese periodo en la mayor parte del mundo. Si en términos generales no se puede suponer, y menos constatar, que la violencia que hoy aqueja a la región se deba a un solo factor, uno de los rasgos más característicos de esta violencia es su código criminal. Aunque hoy por hoy no hay consenso absoluto sobre los factores y las relaciones causales que están en la base de estas violencias, en las dinámicas regionales violentas se advierte la presencia y peso de las economías del narcotráfico y sus derivados. En efecto, las políticas de prohibición de estos mercados no han sido ajenas a estas dinámicas violentas. En numerosos países latinoamericanos el efecto acumulado de décadas de políticas de prohibición ha hecho cada vez más atractivo el negocio de las drogas ilícitas, erosionando a su paso la capacidad de los Estados para mantener y ejercer el monopolio de la violencia organizada y de la impartición de justicia. En varios países las políticas de prohibición y su impacto en el negocio del narcotráfico podrían ser el elemento privilegiado para discernir la lógica de las violencias criminales y de su ramificación en otros tipos de violencia. En Colombia, por ejemplo, más de $40 \%$ de los homicidios están de una manera u otra relacionados con la producción y distribución de drogas. ${ }^{53}$ Los estudios sobre los efectos

${ }^{52}$ Heraldo Muñoz, "Cómo hacer frente a la creciente violencia en el Caribe", PNUD, 20 de marzo de 2012, disponible en http:/ /www.undp.org/content/undp/ es/home/ourperspective/ourperspectivearticles/2012/03/20/how-to-addresssurging-violence-in-the-caribbean-heraldo-mu-oz-/; del mismo autor, "Violencia y crimen: siguen siendo moneda corriente en América Latina”, PNUD, 31 de enero de 2013, disponible en http://www.undp.org/content/undp/es/home/ourperspective/ourperspectivearticles/2013/01/31/violence-crime-still-plague-latinamerica-heraldo-munoz.html; unODc, Global Study on Homicide 2013. Trends, Contexts, Data.

${ }^{53}$ Daniel Mejía y Pascual Restrepo, "The War on Illegal Drug Production and Trafficking: An Economic Evaluation of Plan Colombia”, Documentos Cede, 19, octubre de 2008 . 
políticos de estos fenómenos revelan con una claridad llana el fondo del problema. Al transferir cuantiosos recursos financieros a manos de los traficantes, la prohibición y la gestación de economías ilícitas, han permitido a las organizaciones criminales evadir la persecución y fiscalización, subvertir el orden legal sobornando y comprando a manos llenas a autoridades o coaccionando violentamente a Estados y sociedades en la región. Aunque las estimaciones del valor de estas industrias ilegales son siempre materia de discusión, de lo que no hay duda es de que las divisas generadas en estos circuitos dieron acceso a los narcotraficantes al comercio legal e ilegal de armas abriendo así la posibilidad de establecer sus propios cuerpos de seguridad. Una de las claves para entender el problema de la violencia en la historia de los años recientes de América Latina, de los crímenes atroces y de las rampantes tasas de homicidios que encontramos en muchos países de la región se encuentra en la vasta disponibilidad de armas de fuego. Los cálculos sobre el impacto de estas armas en la violencia homicida en América Latina ubican su contribución muy por arriba del promedio mundial de 42\%. Mientras que en América del Sur hubo presencia de armas de fuego en cerca de $60 \%$ de los homicidios, en América Central la cifra se elevó a casi $70 \%$ del total de asesinatos. Entre tanto, el número estimado del total de armas de fuego en la región oscila entre 45 millones y 80 millones. ${ }^{54}$ Estas tendencias cobraron fuerza al tiempo que la exacerbación de la prohibición provocó el debilitamiento de las instituciones encargadas de perseguir los delitos y de impartir justicia. En medio de este deterioro institucional, no sólo la capacidad para investigar las tendencias crecientes de homicidios naufragó, sino que la impunidad se perfiló como uno de los mayores desafíos que hoy enfrentan los países latinoamericanos.

Aunque el embate de la violencia criminal y de las más horrendas atrocidades delictivas ha asolado de manera más evidente a Colombia, México, Guatemala, Honduras y El Salvador, las ramificaciones

54 Small Arms Survey, 2012; Rachel Stohl y Dough Tuttle, "The Small Arms Trade in Latin America", NACLA Report on the Americas, Nueva York, marzo-abril de 2008. 
de esta crisis se han extendido por buena parte de la región. La trayectoria del efecto "globo", "mariposa" o "cucaracha" ha puesto al descubierto la escasa probabilidad de que los Estados puedan contrarrestar la poderosa lógica comercial que está en la raíz de la prohibición de drogas y del narcotráfico. Una de las consecuencias más ominosas del negocio de las drogas en América Latina ha sido la infiltración y subversión de las instituciones estatales y la amenaza que ello ha supuesto para las poblaciones a las que deberían proteger. A los ojos de algunos la desaparición de 43 estudiantes en México a manos de organizaciones criminales y de cuerpos policiacos locales o la cadena de masacres que fueron perpetradas de manera recurrente y sistemática por grupos paramilitares en Colombia, a menudo en colusión con las fuerzas de seguridad, podrían alcanzar el umbral de crímenes lesa humanidad y por consiguiente de RdeP. ${ }^{55}$

$\mathrm{Al}$ igual que en otras situaciones complejas, la actual crisis de violencia criminal que afecta a la región es resultado de muchos factores y de múltiples causas, que con frecuencia operan en forma conjunta. Desde luego no debe extrañar que estos terribles sucesos hayan atraído la atención y presencia de los actores e instituciones de derechos humanos. La creación y los trabajos de la Comisión Internacional contra la Impunidad en Guatemala (CICIG), la presencia de oficinas del Alto Comisionado de Derechos Humanos en Colombia y México, y de más de una docena de oficinas sub-regionales en el primero, así como la peregrinación en estos países de relatores especiales -sobre minorías, ejecuciones sumarias, arbitrarias o extrajudiciales, tortura o situación de defensores de derechos humanos por mencionar algunos- por no mencionar la invitación del gobierno mexicano a la Comisión Interamericana de Derechos

${ }^{55}$ Véase entre otros, Grupo de Memoria Histórica, ¡Basta ya! Colombia: Memorias de guerra y dignidad, Bogotá, Centro Nacional de Memoria Histórica, Imprenta Nacional, 2013, disponible en http://www.elpais.com.co/elpais/archivos/basta ya.pdf

Open Society Justice Initiative, Atrocidades innegables. Confrontando crimenes de lesa humanidad, Open Society Foundations, 2016, disponible en https://www. opensocietyfoundations.org/sites/default/files/undeniable-atrocities-esp-2ndedition.pdf 
Humanos para coadyuvar en la investigación sobre la desaparición de los 43 estudiantes y la consecuente creación del Grupo Interdisciplinario de Expertos Independientes (GIEI), no podrían explicarse de otra manera. ${ }^{56}$ Aunque los esfuerzos de estos actores han permitido advertir el tamaño de la impunidad que ronda a los homicidios y crímenes atroces que hoy ocurren en la región, una de las preguntas que se plantean expertos y responsables de estas investigaciones tiene que ver con la capacidad de los instrumentos y mecanismos de derechos humanos para solventar y castigar las atrocidades de la violencia criminal. ¿Hasta qué punto los mecanismos e instituciones de derechos humanos que fueron concebidos y desarrollados para lidiar con violaciones masivas perpetradas por instituciones militares y de seguridad del Estado pueden ajustarse y ofrecer una respuesta a la violencia impulsada por una lógica criminal? Como se mencionó ya, la racionalidad de estas medidas e instrumentos se fundó entre otros argumentos en la idea de que bajo el efecto de la presión transnacional la conducta de los gobiernos y sus agencias podría modificarse, en la premisa de que la investigación y castigo de violaciones de derechos humanos podrían reducir la impunidad y por consiguiente la incidencia de estas violaciones, e igualmente importante, en la expectativa de reforma de las instituciones de seguridad y justicia del Estado. No está claro, sin embargo, que la lógica de estos postulados pueda incidir en las conductas violentas impulsadas por la prohibición y el narcotráfico. Como se apuntó antes, las políticas prohibicionistas y de control de drogas han generado las condiciones propicias para que los criminales obtengan el dinero, las armas y el poder que requieren para hacer funcionar su violento negocio.

${ }^{56}$ El GIEI se creó a partir de un acuerdo firmado entre el Estado mexicano, representantes de los 43 estudiantes desaparecidos de Ayotzinapa y la CIDH con tres metas en mente: la elaboración de planes de búsqueda en vida de las personas desaparecidas; análisis técnico de las líneas de investigación para determinar responsabilidades penales; y análisis técnico del Plan de Atención Integral a las Víctimas de los hechos del 26 y 27 de septiembre de 2014. Los reportes elaborados por este grupo de expertos pueden encontrarse en http://www.oas.org/es/cidh/actividades/giei.asp 
Por lo pronto, esta violencia ha empujado a los gobiernos de la región a dar prioridad a los medios y respuestas militares, con todo lo que eso implica para la protección de los derechos humanos. El problema inmediato ha sido un mayor riesgo de violaciones cometidas por las propias fuerzas del Estado, así como un déficit de protección. Pero esta tendencia ha permitido advertir, también, un movimiento regresivo a situaciones que habían sido superadas gracias al activismo de los derechos humanos. Ha ocurrido así, por ejemplo, con el retorno de los militares a funciones de orden público y de policía o con las tendencias de militarización de las policías. Además del altísimo costo en términos de derechos humanos, una conclusión lógica de estas tendencias es que sin duda repercutirán en la capacidad de los países de América Latina para cumplir con sus compromisos internacionales y participar activamente en la evolución normativa de la responsabilidad de proteger.

Traducción de Lorena Murillo S.

\section{Bibliografía}

Basombrío Iglesias, Carlos, "Transitional Justice and Democratic Consolidation: The Peruvian Experience”, en Mónica Serrano y Vesselin Popovski (eds.), After Opression: Transitional Justice in Latin America and Eastern Europe, Tokio, United Nations University Press, 2012, pp. 222-241.

BBC News, "Extradited Fujimori back in Peru", 22 de septiembre de 2007, disponible en http://news.bbc.co.uk/2/hi/7008302.stm

Bermeo, Nancy, Ordinary People in Extraordinary Times: The Citizenry and the Breakdown of Democracy, Princeton, Princeton University Press, 2003.

Booth, Ken y Tim Dunne, "Learning beyond Frontiers", en Tim Dunne y Nicholas Wheeler (eds.), Human Rights in Global Politics, Cambridge, Cambridge University Press, 1999, cap. 12, pp. 303-328

Burt, Jo-Marie, "Guilty as Charged: The Trial of Former Peruvian President Alberto Fujimori for Human Rights Violations", The International Journal of Transitional Justice, vol. 3, 2009. 
Carothers, Thomas. "The Resurgence of US Political Development Assistance to Latin America in the 1980s", en Laurence Whitehead (ed.), The International Dimensions of Democratization. Europe and the Americas, Oxford, Oxford University Press, 2001, pp. 128-136.

Couffignal, Georges, La nouvelle Amérique Latine. Laboratoire politique de l'Occident, París, Presses de Science Po, 2013.

Dewar, Diego y Mónica Serrano, "México y la Responsabilidad de Proteger", en Guadalupe González, Olga Pellicer y Natalia Saltalamacchia (eds.), México y el Multilateralismo del siglo XXI, México, Siglo XXI Editores, 2015, pp. 170-206.

Domingo, Pilar, "Accountability: The Rule of Law and Transitional Justice in Latin America”, en Mónica Serrano y Vesselin Popovski (eds.), After Opression: Transitional Justice in Latin America and Eastern Europe, Tokio, United Nations University Press, 2012, pp. 41-63.

Domínguez, Jorge I., "International Cooperation in Latin America. The Design of Regional Institutions by Slow Accretion”, en Amitav Acharya y Alastair I. Johnston (eds.), Crafting Cooperation: Regional International Institutions in Comparative Perspective, Cambridge, Cambridge University Press, 2008, pp. 83-128.

Donnelly, Jack, "Universal Human Rights: A Critique", en Tim Dunne y Nicholas Wheeler (eds.), Human Rights in Global Politics, Cambridge, Cambridge University Press, 1999.

Engstrom, Par y Andrew Hurrell, "Why the Human Rights Regime in the Americas Matters", en Mónica Serrano y Vesselin Popovski (eds.), Human Rights Regimes in the Americas, Tokio, United Nations University Press, 2010, pp. 29-55.

Farer, Tom, "The Rise of the Inter-American Human Rights Regime: No Longer a Unicorn, Not Yet an Ox”, Human Rights Quarterly, vol. 17, 1997.

Foweraker, Joe y Roman Krznaric, "The Uneven Performances of Third Wave Democracies: Electoral Politics and the Imperfect Rule of Law in Latin America”, Latin American Politics and Society, vol. 44, núm. 2, 2002, pp. 35-37.

Foweraker, Joe y Todd Landman, "Constitutional Design and Democratic Performance", Democratization, vol. 9, núm. 2, 2002, pp. 43-66.

Fitch, Samuel J., The Armed Forces and Democracy in Latin America, Baltimore, The Johns Hopkins University Press, 1998. 
Frank, Thomas M., "The Emerging Right to Democratic Governance", American Journal of International Law, vol. 86, núm. 1, enero de 1992.

Fuentes, Claudio, "The Unlikely Outcome: Transitional Justice in Chile 1990-2008”, en Mónica Serrano y Vesselin Popovski (eds.), After Oppression: Transitional Justice in Latin America and Eastern Europe, Tokio, United Nations University Press, 2012, pp. 116-142.

Garretón Manuel Antonio, "Human Rights in Processes of Democratization”, Journal of Latin American Studies, vol. 26, 1994, pp. 221-234.

Goldman, Robert K., "History and Action: The Inter-American Human Rights System and the Role of the Inter-American Commission on Human Rights", Human Rights Quarterly, vol. 31, 2009.

Goldstone, Richard J., "The Role of the ICC", en Robert I. Rotberg (ed.), Mass Atrocity Crimes: Preventing Future Outrages, Washington, D. C., Brookings Institution Press, 2010, pp. 55-68.

González Ocantos, Ezequiel, "Persuade them or Oust Them", Comparative Politics, vol. 46, núm. 4, 2014, pp. 479-498.

Hubert, Don, "The Landmine Ban: A Case Study in Humanitarian Advocacy", con un prefacio de S. Neil MacFarlane, Providence, The Thomas J. Watson Jr. Institute for International Studies, Brown University, 2000, 93 pp. (Occasional Papers, 42), disponible en: http:/ /www.wats oninstitute.org/pub/op42.pdf

Human Rights Watch, "Brazil: Panel Details 'Dirty War' Atrocities: Truth Commission Identifies Abusers, Calls for Prosecutions”, 10 de diciembre de 2014, disponible en http:/ / www.hrw.org/news/2014/12/ 10/brazil-panel-details-dirty-war-atrocities.

Hurrell, Andrew, "International Society and the Study of Regimes. A Reflective Approach", en Wolker Rittberg (con Peter Mayer) (ed.), Regime Theory and International Relations, Oxford, Clarendon Press, 1993, pp. 206-226.

, "An Emerging Security Community in South America", en Emmanuel Adler y Michael Barnett (eds.), Security Communities, Cambridge, Cambridge University Press, 1998, pp. 228-264.

, "Regional Powers and the Global System from a Historical Perspective", en Daniel Flemes (ed.), Regional Leadership in the Global System: Ideas, Interests and Strategies of Regional Powers, Farnham, Ashgate, 2010, pp. 15-30.

Kai, Ambos, Ezequiel Malarino y Gisela Elsner (eds.), Sistema interamericano 
de protección de los derechos humanos y derecho penal internacional, Montevideo, Fundación Konrad Adenauer, 2010.

Loveman, Brian, For La Patria: Politics and the Armed Forces in Latin America, Wilmington, Scholarly Resources, 1999. y Thomas M. Davis (eds.), The Politics of Antipolitics: The Military in Latin America, $3^{\text {a }}$ ed., rev. y amp., Oxford, Scholarly Resources, 1997. Lowenthal, Abraham F., "Two Hundred Years of American Foreign Policy: The United States and Latin America: Ending the Hegemonic Presumption", Foreign Affairs, octubre de 1976.

Macaulay, Fiona, "Human Rights in Context: Brazil", en Mónica Serrano y Vesselin Popovski (eds.), Human Rights Regimes in the Americas, Tokio, United Nations University Press, 2010, pp. 133-155.

Mejía, Daniel y Pascual Restrepo, "The War on Illegal Drug Production and Trafficking: An Economic Evaluation of Plan Colombia”, Documentos Cede, 19, Universidad de los Andes, CEDE, octubre de 2008.

Morsink, Johannes, The Universal Declaration of Human Rights: Origins, Drafting, and Intent, Filadelfia, University of Pennsylvania Press, 1999.

Moyne Samuel, "The Universal Declaration of Human Rights of 1948 in the History of Cosmopolitanism", Critical Inquiry, vol. 40, núm. 4, 2014.

Muñoz, Heraldo, "The oAs and Democratic Governance", Journal of Democracy, vol. 4, núm. 3, julio de 1993.

— , "Cómo hacer frente a la creciente violencia en el Caribe", PNUD, 20 de marzo de 2012, disponible en http://www.undp.org/content/ undp/es/home/ourperspective/ourperspectivearticles/2012/03/ 20/how-to-address-surging-violence-in-the-caribbean-heraldo-mu-oz-/ -, "Violencia y crimen: siguen siendo moneda corriente en América Latina”, PNUD, 31 de enero de 2013, disponible en http://www. undp.org/content/undp/es/home/ourperspective/ourperspectivearticles/2013/01/31/violence-crime-still-plague-latin-america-heraldo-munoz.html

Ochoa, Paulina, "Paradoxes of Popular Sovereignty: A View from Spanish America", The Journal of Politics, vol. 74, núm. 4, octubre de 2012.

Odelberg, Wilhelm (ed.), Les Prix Nobel: The Nobel Prizes 1982, Estocolmo, Nobel Foundation, 1983.

Padgen, Anthony, "Human Rights, Natural Rights and European Imperial Legacy”, Political Theory, vol. 31, núm. 2, abril de 2003. 
Pion-Berlin, David, The Ideology of State Terror: Economic Doctrine and Political Repression in Argentina and Peru, Boulder, Lynne Rienner, 1989.

- Civil-Military Relations in Latin America: New Analytical Perspectives, Chapel Hill, University of North Carolina Press, 2001.

Potash, Robert A., The Army and Politics in Argentina, 1945-1962: Perón to Frondizi, Londres, The Athione Press, 1980.

Restrepo, Elvira María. "Transitional Justice without a Compass: Paramilitary Demobilization in Colombia”, en Mónica Serrano y Vesselin Popovski (eds.), After Opression: Transitional Justice in Latin America and Eastern Europe, Tokio, United Nations University Press, 2012, pp. 143169.

Rock, David P., “Military Politics in Argentina 1966-1973”, en Brian Loveman y Thomas J. Davies (eds.), The Politics of Antipolitics: The Military in Latin America, Lincoln, University of Nebraska, 1978.

Romero, Simón, "Court Approves Extradition of Fujimori”, The New York Times, 21 de septiembre de 2007, disponible enhttp://www.nytimes. com/2007/09/21/world/americas/22chile.html?fta=y\&_r=0

Rotberg Robert I., "Deterring Mass Atrocity Crimes: The Cause of Our Era", en Robert I. Rotberg (ed.), Mass Atrocity Crimes: Preventing Future Outrages, Washington, D. C., Brookings Institution Press, 2010, pp. 1-24.

Serrano, Mónica, "Latin America: The Dilemmas of intervention", en Albrecht Schnabel y Ramesh Thakur (eds.), Kosovo and the Challenge of Humanitarian Intervention: Selective Indignation, Collective Action and International Citizenship, Tokio, United Nations University Press, 2000, pp. 223-244.

, "The Human Rights Regime in the Americas: Theory and Reality”, en Mónica Serrano y Vesselin Popovski (eds.), Human Rights Regimes in the Americas, Tokio, United Nations University Press, 2010, pp. 1-28.

__ , "Transitional Justice and Democratic Consolidation", en Mónica Serrano y Vesselin Popovski (eds.), After Opression: Transitional Justice in Latin America and Eastern Europe, Tokio, United Nations University Press, 2012, pp. 463-484.

Sikkink, Kathryn, "Human Rights, Principled Issue-Networks, and Sovereignty in Latin America", International Organization, vol. 47, núm. 3, verano de 1993. 
, Mixed Signals: US Human Rights Policy towards Latin America, Ithaca, Cornell University Press, 2004.

, The Justice Cascade: How Human Rights Prosecutions Are Changing World Politics, Nueva York y Londres, W. W. Norton \& Company, 2011. — , "Latin American Countries as Norm Protagonists of the Idea of International Human Rights", sección especial de "Principles from the Periphery: The Neglected Southern Sources of Global Norms", Global Governance, vol. 20, núm. 3, julio-septiembre de 2014.

Small Arms Survey 2012, Cambridge, Cambridge University Press, 2012. Smulovitz, Catalina, “'The Past Is Never Dead': Accountability and Justice for Past Human Rights Violations in Argentina”, en Mónica Serrano y Vesselin Popovski (eds.), After Oppression: Transitional Justice in Latin America and Eastern Europe, Tokio, United Nations University Press, 2012, pp. 64-85.

Stepan, Alfred C., The Military in Politics: Changing Patterns in Brazil, Princeton, Princeton University Press, 1971.

—, Rethinking Military Politics: Brazil and the Southern Cone, Princeton, Princeton University Press, 1988.

Stohl, Rachel y Dough Tuttle, "The Small Arms Trade in Latin America", NACLA Report on the Americas, Nueva York, marzo-abril de 2008.

Tanner, Lauri R., "Interview with Judge Antônio A. Cançado Trindade, Inter-American Court of Human Rights", Human Rights Quarterly, vol. 31, núm. 4, noviembre de 2009, pp. 985-1005.

Valenzuela, Arturo, "Six Years of Military Rule in Chile: A Rapporteur's Report", Washington, D. C., Woodrow Wilson Center, Latin American Program, Working Papers 109, 1982.

Valenzuela, Samuel J. y Arturo Valenzuela (eds.), Military Rule in Chile: Dictatorship and Oppositions, Baltimore, The Johns Hopkins University Press, 1986.

Whitehead, L., "Democratization and Human Rights in the Americas", en Louise Fawcett y Mónica Serrano (eds.), Regionalism and Governance in the Americas: Continental Drift, Basingstoke, Palgrave MacMillan, 2005, pp. 221-234.

llan, 2006. 